\title{
Asthma and genes encoding components of the vitamin $D$ pathway
} Yohan Bossé ${ }^{1,2}$, Mathieu Lemire ${ }^{3}$, Audrey H Poon ${ }^{4,5}$, Denise Daley ${ }^{6}$, JianQing $\mathrm{He}^{6}$, Andrew Sandford ${ }^{6}$, John H White ${ }^{7}$, Alan L James 8 , Arthur William Musk ${ }^{9}$, Lyle J Palmer ${ }^{10}$, Benjamin A Raby ${ }^{4,5,11}$, Scott T Weiss ${ }^{4,5}, 12$, Anita L Kozyrskyj ${ }^{13}$, Allan Becker ${ }^{13}$, Thomas J Hudson*3 and Catherine Laprise ${ }^{14,15}$

\begin{abstract}
Address: ${ }^{1}$ Institut universitaire de cardiologie et de pneumologie de Québec, Québec, Canada, ${ }^{2}$ Laval University Hospital Research Center (CRCHUL), Québec, Canada, ${ }^{3}$ Ontario Institute for Cancer Research, Toronto, Canada, ${ }^{4}$ The Channing Laboratory, Department of Medicine, Brigham and Women's Hospital, Boston, MA, USA, ${ }^{5}$ Harvard Medical School, Boston, MA, USA, ${ }^{6} J a m e s$ Hogg iCAPTURE Centre for Cardiovascular and Pulmonary Research, St Paul's Hospital, University of British Columbia, Vancouver, Canada, ${ }^{7}$ Departments of Physiology and Medicine, McGill University, Montreal, Canada, ${ }^{8}$ West Australian Sleep Disorders Research Institute, Sir Charles Gairdner Hospital, Western Australia, ${ }^{9}$ Department of Respiratory Medicine, Sir Charles Gairdner Hospital, Western Australia, ${ }^{10}$ UWA Centre for Genetic Epidemiology and Biostatistics, The University of Western Australia, Western Australia, ${ }^{11}$ Division of Pulmonary and Critical Care Medicine, Department of Medicine, Brigham and Women's Hospital, Boston, MA, USA, ${ }^{12}$ The Center for Genomics Medicine, Department of Medicine, Brigham and Women's Hospital, Boston, MA, USA, ${ }^{13}$ Department of Pediatrics and Child Health, Faculty of Medicine, University of Manitoba, Winnipeg, Canada, ${ }^{14}$ Université du Québec à Chicoutimi, Chicoutimi, Canada and ${ }^{15}$ Community Genomic Medicine Centre, University of Montreal, Chicoutimi University Hospital, Chicoutimi, Canada

Email: Yohan Bossé - yohan.bosse@crhl.ulaval.ca; Mathieu Lemire - mathieu.lemire@oicr.on.ca; Audrey H Poon - audrey.poon@channing.harvard.edu; Denise Daley - ddaley@mrl.ubc.ca; Jian-Qing He - JHe@mrl.ubc.ca; Andrew Sandford - ASandford@mrl.ubc.ca; John H White - john.white@mcgill.ca; Alan L James - Alan.James.SCGH@health.wa.gov.au; Arthur William Musk - Bill.Musk@uwa.edu.au; Lyle J Palmer - lyle@cyllene.uwa.edu.au;

Benjamin A Raby - Benjamin.Raby@channing.harvard.edu; Scott T Weiss - Scott.Weiss@channing.harvard.edu;

Anita L Kozyrskyj - Anita.Kozyrskyj@capitalhealth.ca; Allan Becker - becker@ms.umanitoba.ca; Thomas J Hudson* - tom.hudson@oicr.on.ca; Catherine Laprise - Catherine_Laprise@uqac.ca

* Corresponding author
\end{abstract}

Published: 24 October 2009

Respiratory Research 2009, 10:98 doi:10.1 186/1465-9921-10-98
Received: 2 June 2009

Accepted: 24 October 2009

This article is available from: http://respiratory-research.com/content//0/I/98

(C) 2009 Bossé et al; licensee BioMed Central Ltd.

This is an Open Access article distributed under the terms of the Creative Commons Attribution License (http://creativecommons.org/licenses/by/2.0), which permits unrestricted use, distribution, and reproduction in any medium, provided the original work is properly cited.

\begin{abstract}
Background: Genetic variants at the vitamin D receptor (VDR) locus are associated with asthma and atopy. We hypothesized that polymorphisms in other genes of the vitamin $D$ pathway are associated with asthma or atopy.

Methods: Eleven candidate genes were chosen for this study, five of which code for proteins in the vitamin D metabolism pathway (CYP27A I, CYP27BI, CYP2RI, CYP24AI, GC) and six that are known to be transcriptionally regulated by vitamin D (ILI0, ILIRLI, CD28, CD86, IL8, SKIIP). For each gene, we selected a maximally informative set of common SNPs (tagSNPs) using the Europeanderived (CEU) HapMap dataset. A total of 87 SNPs were genotyped in a French-Canadian family sample ascertained through asthmatic probands (388 nuclear families, 1064 individuals) and evaluated using the Family Based Association Test (FBAT) program. We then sought to replicate the positive findings in four independent samples: two from Western Canada, one from Australia and one from the USA (CAMP).
\end{abstract}


Results: A number of SNPs in the ILI 0, CYP24AI, CYP2RI, ILIRLI and CD86 genes were modestly associated with asthma and atopy $(p<0.05)$. Two-gene models testing for both main effects and the interaction were then performed using conditional logistic regression. Two-gene models implicating functional variants in the ILIO and VDR genes as well as in the ILIO and ILIRLI genes were associated with asthma $(p<0.0002)$. In the replicate samples, SNPs in the ILIO and CYP24AI genes were again modestly associated with asthma and atopy $(p<0.05)$. However, the SNPs or the orientation of the risk alleles were different between populations. A two-gene model involving ILIO and VDR was replicated in CAMP, but not in the other populations.

Conclusion: A number of genes involved in the vitamin $D$ pathway demonstrate modest levels of association with asthma and atopy. Multilocus models testing genes in the same pathway are potentially more effective to evaluate the risk of asthma, but the effects are not uniform across populations.

\section{Background}

Asthma is a heterogeneous respiratory disease characterized by chronic inflammation of the airways associated with recurrent symptoms that range from mild to debilitating [1]. Asthma is in large part attributable to genetic factors [2]. However, identifying the causal genes has been a daunting task due to the inherent complexity of the disease as well as methodological issues related to finding genes of complex diseases [3]. The emerging picture from the literature suggests hundreds of genes are associated with asthma or asthma-related phenotypes [4,5]. Major efforts are currently underway to validate these genes in larger populations as well as to identify novel genes using new technology-driven approaches such as genome-wide single-nucleotide-polymorphism (SNP) association studies [6-8].

The innate and adaptive immune systems play an important role in the pathogenesis of asthma. Many genes involved in inflammation and immunoregulation pathways have been associated with asthma [3]. The immune system is complex in nature with multiple redundant and interfering pathways. Recently, the vitamin D pathway has emerged as a new pathway contributing to the outcome of immune responses [9-12]. The vitamin D pathway has long been recognized for its endocrine actions on bone and mineral homeostasis. However, growing knowledge has elucidated autocrine and paracrine roles for the vitamin D system with respect to cell growth, proliferation and differentiation as well as in immune regulation [13]. The biologically active form of vitamin $\mathrm{D}(1 \alpha, 25$-dihydroxyvitamin $\mathrm{D}_{3}$ ), also known as calcitriol, mediates its effect by binding to the nuclear vitamin D receptor (VDR). Upon activation, the VDR ligand/receptor complex alters the transcription rate of many genes involved in a wide spectrum of biological responses [14].

The hypothesis that the vitamin D pathway plays a role in autoimmune diseases such as asthma, originates from the identification of VDR in immunological relevant cells, including antigen-presenting cells and activated T lymphocytes $[15,16]$. How VDR affects immune cell populations, cytokine secretion, and production is not entirely known, but previous evidence suggests that VDR activation may cause a developmental shift of T helper (Th) cells toward type $2[17,18]$. The hypothesis that VDR plays a role in asthma was also reinforced by the resistance of VDR knock-out mice to experimentally induced asthma [19]. These mice fail to develop airway inflammation, eosinophilia, or airway hyperresponsiveness, despite high IgE concentration and elevated Th2 cytokines. Recently, a functional polymorphism (FokI, rs2228570) in the VDR gene was shown to have a functional impact on the immune system by interfering with the signaling of transcription factors important in immune-mediated diseases such as NF- $\kappa$ B and NFAT [20]. Taken together, these studies clearly support $V D R$ as a possible candidate gene for asthma.

Two groups co-reported that genetic variants within the VDR gene were associated with asthma [21,22]. In a French-Canadian founder population, Poon et al. [21] demonstrated that six SNPs located between intron 2 and exon 9 spanning $28 \mathrm{~kb}$ of the VDR gene were associated with asthma. Linkage disequilibrium (LD) patterns within this population revealed the presence of two blocks (block 1 and 2) containing 3 and 4 common haplotypes, respectively. One haplotype within each block was overtransmitted to affected offspring. By sequencing the promoter, exons and surrounding regions, they excluded novel missense mutations that could explain the observed association. In a second study, Raby et al. [22] found significant associations between VDR variants and asthma in two independent studies. They first screened seven candidate genes that map to the centromeric region of chromosome 12 in the Childhood Asthma Management Program (CAMP) study. Only one SNP located in the VDR gene demonstrated evidence of association with asthma. Consistent with the French-Canadian population, two LD blocks were observed, each with three common haplo- 
types. The 3' haplotype block in the CAMP study was significantly associated with asthma. To exclude the possibility that neighboring genes cause the association, the authors genotyped 29 SNPs in a $330 \mathrm{~kb}$ region surrounding the VDR gene. None of these SNPs were associated with asthma, leaving VDR as the most likely causal gene. Their finding was then replicated in the Nurses' Health Study (NHS) [22]. In that study, four of the six genotyped SNPs within the VDR gene were associated with asthma. However, it should be noted that the direction of the association in NHS was opposite to the effects seen in CAMP, but similar to the findings in the FrenchCanadian population. Taken together, these data suggested that the VDR locus harbors variants that contribute to asthma, but the orientation of the risk allele is inconsistent across populations.

Numerous metabolic pathways are likely to play a major role in complex diseases. It is necessary to study the components of these pathways to gain a more comprehensive genetic view of the susceptibility conferred by variants located in closely related genes $[23,24]$. Accordingly, we hypothesized that polymorphisms in other genes involved in the vitamin D system are associated with asthma or atopy.

\section{Methods}

\section{Population}

Subjects were from the Saguenay-Lac-Saint-Jean (SLSJ) asthma study, which consists of French-Canadian families ascertained through asthmatic probands. Probands were included in the study if they fulfilled at least two of the following criteria: 1) a minimum of three clinic visits for acute asthma within one year; 2 ) two or more asthmarelated hospital admissions within one year; or 3) steroid dependency, defined by either six month's use of oral, or one year's use of inhaled corticosteroids. A total of 1064 individuals from 388 nuclear families were included in the present analyses. Families were included in the study if at least one parent was available for phenotypic assessment, at least one parent was unaffected, and all four grandparents were of French-Canadian origin. Family members were considered asthmatics if both a selfreported history of asthma and a history of physiciandiagnosed asthma were recorded, or by clinical evaluation following a methacholine provocation test. Skin-prick tests were performed for 26 inhalant allergens and subjects were considered atopic if they had at least one positive response (wheal diameter $\geq 3 \mathrm{~mm}$ at $10 \mathrm{~min}$ ) [25]. Spirometry, methacholine challenge and IgE measurements are described in detail elsewhere [21]. Table 1 presents the characteristics of the subjects. The SLSJ local ethics committee approved the study, and all subjects gave informed consent.

\section{Replication samples}

Data from the Canadian Asthma Primary Prevention Study (CAPPS) study, the Study of Asthma Genes and the Environment (SAGE) birth cohort and the Busselton Health Study (BHS) were used to replicate the findings. The Childhood Asthma Management Program (CAMP) study was also used to replicate a specific gene-gene (VDRIL10) interaction models. The CAPPS and SAGE studies have been described elsewhere [26]. Briefly, the CAPPS study was initiated in 1995 to assess the effectiveness of a multifaceted intervention program in the primary prevention of asthma in high-risk infants $[27,28]$. High-risk infants were identified before birth as having at least one first-degree relative with asthma or two first-degree relatives with other IgE-mediated allergic diseases. A total of 549 children and their parents forming 545 families were enrolled in the study during the second and third trimes-

Table I: Characteristics of the subjects in the Saguenay-Lac-Saint-Jean study.

\begin{tabular}{|c|c|c|c|c|}
\hline & $\begin{array}{l}\text { All subjects } \\
(n=1064)\end{array}$ & $\begin{array}{l}\text { Probands } \\
(n=210)\end{array}$ & $\begin{array}{l}\text { Affected members } \\
\quad(n=320)\end{array}$ & $\begin{array}{l}\text { Unaffected members } \\
\qquad(n=534)\end{array}$ \\
\hline Age (years) & $39.7 \pm 22.1$ & $17.6 \pm 9.4$ & $40.0 \pm 19.5$ & $48.3 \pm 21.1$ \\
\hline Male: Female ratio & 0.80 & 0.86 & 0.68 & 0.85 \\
\hline Mean age of onset (years) & $16.5 \pm 17.0$ & $7.4 \pm 7.6$ & $22.3 \pm 18.7$ & NA \\
\hline $\mathrm{FEV}_{1}(\%$ predicted $)$ & $94.1 \pm 19.8$ & $92.5 \pm 16.1$ & $88.9 \pm 23.2$ & $99.1 \pm 17.2$ \\
\hline PEFR (\%) & $6.4 \pm 4.6$ & $7.3 \pm 4.2$ & $7.4 \pm 5.9$ & $5.0 \pm 2.9$ \\
\hline $\mathrm{PC}_{20}(\mathrm{mg} / \mathrm{ml})$ & $21.1 \pm 24.9$ & $5.1 \pm 8.5$ & $8.8 \pm 15.4$ & $39.4 \pm 24.9$ \\
\hline Serum IgE (mg/L) & $452.7 \pm 1619.2$ & $720.3 \pm 1919.9$ & $531.4 \pm 1960.8$ & $244.8 \pm 1005.9$ \\
\hline Atopy (n) & $593(56.3 \%)$ & $|7|(81.8 \%)$ & $218(69.2 \%)$ & $204(38.6 \%)$ \\
\hline \multicolumn{5}{|l|}{ Smoking Status (n) } \\
\hline Never & $55 \mathrm{I}(52.6 \%)$ & $173(84.0 \%)$ & $154(48.7 \%)$ & $224(42.7 \%)$ \\
\hline Ex-smoker & $291(27.8 \%)$ & II (5.3\%) & $100(31.7 \%)$ & $180(34.3 \%)$ \\
\hline Smoker & 205 (19.6\%) & $22(10.7 \%)$ & $62(19.6 \%)$ & $121(23.1 \%)$ \\
\hline
\end{tabular}

Values are means $\pm S D$ for quantitative variables.

$\mathrm{FEV}_{1}$, Forced expiratory volume in one second; $\mathrm{PC}_{20}$, Concentration of methacholine inducing a $20 \%$ fall in FEV ${ }_{1}$; PEFR, Peak expiratory flow rate (morning-evening variation). 
ter of pregnancy. The children were followed since birth and were assessed by a pediatric allergist for the presence of asthma and allergies. Atopy was defined by skin-prick test. A total of 16 allergens were tested and the diagnosis was positive if at least one wheal $\geq 3 \mathrm{~mm}$ than the negative control was observed. Children with 7 year follow-up data and DNA were included in the current study (380 children/families). The SAGE study is a population-based cohort of 16,320 children born in the province of Manitoba, Canada, between January 1, 1995 and December 31, 1995. Parents of these children were first survey by mail in 2002. A subset of children was then invited to join the study at age 8-10 years. This subset included children with parent-declared asthma and children without asthma. A total of 723 families were recruited into the study. All recruited children underwent clinical assessment of asthma by a pediatric allergist. Skin prick testing for 16 allergens was used to define atopy. In the two latter studies (SAGE and CAPPS), children affected with asthma/ atopy and their parents were genotyped and analysed in trios. In contrast, the BHS was analysed using a case-control design. This study comprised a series of six cross-sectional health surveys that took place every three years from 1966 to 1981 in all adults and children residing in the Shire of Busselton, Western Australia and a follow-up study of all previous participants (residing within and outside this Shire) in 1994/1995. Busselton is a coastal town in the South West region of Western Australia with a population that is predominantly of European origin. In the present case-control study, all subjects $(n=1395,751$ controls and 644 cases) who attended both the 1981 and the 1994 survey and who had a diagnosis of asthma as well as available DNA were included. Subjects were considered to have asthma if they answered yes to the question "Has your doctor ever told you that you had asthma/ bronchial asthma?" in a written questionnaire at either survey. Subjects were considered controls if they answered no at both surveys. Skin prick testing for 12 allergens was used to define atopy. Finally, CAMP is a multicentered North American clinical trial designed to investigate the long-term effects of inhaled anti-inflammatory medications in children with mild to moderate asthma [29,30]. A total of 1625 individual members of 428 non-Hispanic white nuclear families were included in the present analyses. This represents the subset non-Hispanic with CAMP families with available SNP genotype data at both the VDR and IL10 loci. The diagnosis of asthma was based on a methacholine provocation test and one or more of the following criteria for at least 6 months in the year before recruitment: 1) asthma symptoms at least two times per week, 2) at least two uses per week of an inhaled bronchodilator, and 3 ) daily asthma medication. A local ethics committee approved the protocol independently in each study. Written informed consent was obtained from all study participants.

\section{Gene selection}

Eleven candidate genes were chosen for this study. Figure 1 is a cartoon of the vitamin D pathway that illustrates the implication of each gene selected. Briefly, genes encoding key components of the vitamin D pathway were chosen, which include: enzymes responsible for the activation and inactivation vitamin D (CYP27A1, CYP27B1, CYP2R1 and CYP24A1) [31,32]; the vitamin D binding protein (GC) that binds to vitamin D and its plasma metabolites and transports them to target tissues; SKIIP, also known as NCoA62/SKIP, that serves as a coactivator a vitamin Dmediated transcription [33]; and five revevant genes for asthma that are known to be transcriptionally regulated by vitamin D (IL10, IL1RL1, CD28, CD86 and IL8) [14].

\section{SNP selection}

SNPs were selected using the CEPH genotype dataset from phase 1 of the International HapMap project [34]. The genotype data were downloaded from the genomic region covering ten kilobases up- and downstream of each gene. A maximally informative set of SNPs was selected using a pairwise tagging algorithm described by Carlson et al. [35]. A Perl program, called ldSelect http://droog.gs.wash ington.edu/ldSelect.html, was used to select the SNPs in each gene. Briefly, this program analyzes the pattern of LD between SNPs and forms bins of SNPs in LD based on an $r^{2}$ threshold. The algorithm ensures that all pairwise LD values between SNPs in the same bin exceed the $\mathrm{r}^{2}$ threshold. Accordingly, any SNP in a bin can serve as a proxy (tagSNP) for all other SNPs in the same bin. Only one tagSNP needs to be typed per bin. At this level, nonsynonymous SNPs genotyped in the HapMap dataset were prioritized using the "-required" option. Similarly, some SNPs were prioritized based on the type of variation $(\mathrm{A} / \mathrm{T}$, $\mathrm{C} / \mathrm{T}$, etc) to meet the genotyping technology requirement. The minor allele frequency and the $\mathrm{r}^{2}$ thresholds were set at 0.05 and 0.8 , respectively, using the "-freq" and "-r2" options. Known nonsynonymous SNPs or functional variants not genotyped in the HapMap dataset were also selected for genotyping. Selected SNPs and their characteristics are shown in additional file (see Additional file 1). The location of SNPs relative to the gene structure is illustrated in Additional file 2.

\section{Genotyping}

In the SLSJ study, a total of 87 SNPs were genotyped using the SNP stream ${ }^{\circledR}$ UHT technology [36]. Primers were designed using FastPCR version 3.8.78 for multiplex PCR [37]. Single base extension primers were designed using Autoprimer.com (Beckman Coulter). The protocol and reaction conditions were performed in accordance with the manufacturer [36]. SNPs were genotyped in different panels that were organized by grouping SNPs with the same type of variation $(\mathrm{A} / \mathrm{T}, \mathrm{C} / \mathrm{T}$, etc) and by respecting the 12-plex maximum capacity of the system. For the rep- 


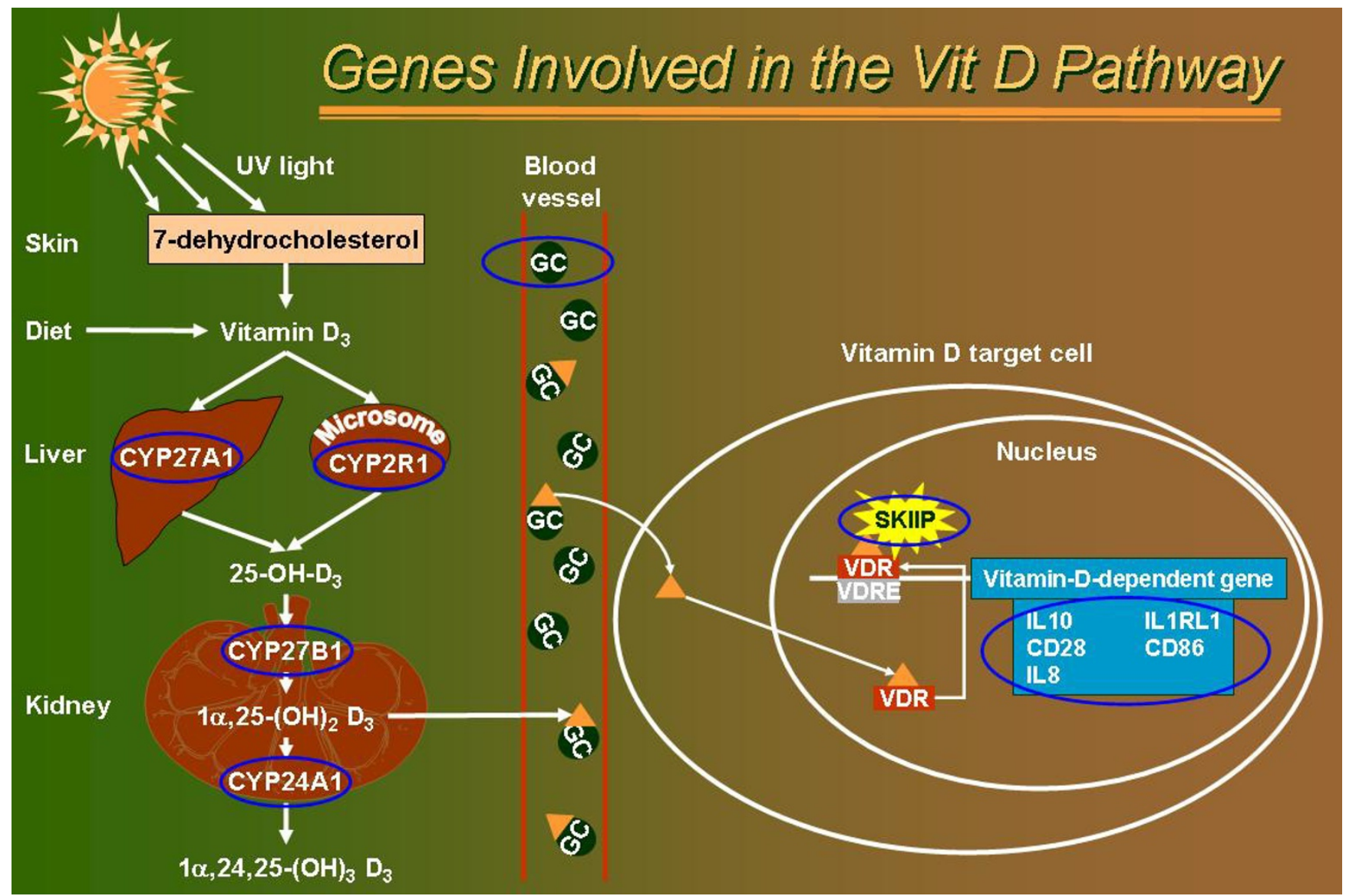

Figure I

Genes involved in the vitamin $\mathbf{D}$ pathway. Vitamin $\mathrm{D}_{3}$ comes from the diet but is mostly produced in the skin by the photolytic cleavage of 7-dehydrocholesterol. From vitamin $D_{3}$, two enzymatic activation steps are required to produce the biologically active form of vitamin $D\left[I \alpha, 25-(\mathrm{OH})_{2} \mathrm{D}_{3}\right]$. CYP27AI and CYP2RI genes encode enzymes with 25-hydroxylase activity that catalyze the $C-25$ hydroxylation of vitamin $D_{3}$. A final activation enzyme encoded by CYP27B/ subsequently catalyzes the rate-limiting $\mathrm{C}-\mathrm{I}$ hydroxylation step in $\mathrm{I} \alpha, 25-(\mathrm{OH})_{2} \mathrm{D}_{3}$ synthesis. The later enzyme is tightly-regulated in the kidney by calcium homeostatic signals, but also strongly induced by immune inputs (e.g. TLR signaling) in many cells of the immune system [12] (not depicted). The active form of vitamin $D, I \alpha, 25-(\mathrm{OH})_{2} D_{3}$ (orange triangle), is then transport to vitamin $\mathrm{D}$ target cells by the vitamin $D$ binding protein (encoded by the GC locus) or is metabolically inactivated by the 24-hydroxylase enzyme (encoded by the CYP24AI locus). In vitamin D target cells, $I \alpha, 25-(\mathrm{OH})_{2} \mathrm{D}_{3}$ translocates to the nucleus and binds to the vitamin $D$ receptor (VDR). The ligand/receptor complex binds vitamin $D$ response element (VDRE) located in the promoter region of target genes. The DNA-bound complex interacts with nuclear coregulators, such as SKIIP [33], and alters the rate of gene transcription. Five genes having a VDRE or/and being transcriptionally regulated by vitamin $D$ stimulation are shown (blue square). Genes selected for genotyping in the SLSJ study are circled in blue.

lication studies (CAPPS, SAGE and BHS), 52 SNPs located in five genes were genotyped using the Illumina GoldenGate assay [38] as part of a larger SNP genotyping panel http://www.genapha.ca. SNP genotypes in CAMP available from prior analyses were generated for VDR [22] and IL10 [39] using the MassARRAY platform (Sequenom, San Diego, CA) and SNaPShot (Applied Biosystems, Forrest City, CA), respectively, as previously described.

\section{Statistical analyses}

Mendelian inheritance incompatibilities were inspected using Pedmanager version 0.9 and Hardy-Weinberg equilibrium was evaluated using a $\chi^{2}$ test among parents. For the SLSJ, CAPPS and SAGE studies the Family Based Association Test (FBAT) program was used to test association with single SNPs [40]. All tests were performed with an additive model using the empirical variance-covariance estimator that adjusts for the correlation among sibling genotypes and for multiple nuclear families within a single pedigree. The FBAT test provides a Z-statistic with the 
corresponding $\mathrm{p}$ value. A positive $\mathrm{Z}$-statistic is indicative of a high-risk allele and a negative $\mathrm{Z}$-statistic is indicative of a protective allele. In the BHS, the single SNP associations were evaluated using the Cochran-Armitage test for trend with additive coding of alleles. Genes showing at least one SNP with a $\mathrm{p}<0.05$ in the SLSJ collection were considered for validation in the other populations. Our strategy to deal with multiple testing was to replicate the associations in independent populations instead of using an adjusted p value. LD values were evaluated using the $\mathrm{r}^{2}$ metrics and calculated with Haploview 3.32 [41]. Power calculations for the four study populations were recently described [42].

Gene-gene interactions were evaluated for asthma and atopy using a multilocus analysis method following the framework described in Millstein et al. [23]. This strategy is based on likelihood-ratio tests that used a log-additive coding scheme, where genotypes aa, Aa, and AA are coded as 0,1 , and 2, respectively. Briefly, the analyses were performed in two stages. In stage one, single SNP tests of associations were evaluated by contrasting the null hypothesis of no association with the alternative hypothesis. The threshold for significance for stage one of the gene-gene interaction tests was then adjusted for multiple testing using the Bonferroni correction. In stage two, a full two-gene interaction model, including the two main effects and the interaction term, was tested against the reduced model that includes only the main effects that were declared significant in the first stage, if any. This strategy avoids retesting the same effects detected in stage one. While the framework of Millstein et al. [23] was described for a case-control dataset, it can easily be adapted to a case-parent design by following the case/ pseudocontrol design described by Cordell et al. [43], where each case is matched with three pseudocontrols derived from the untransmitted parental alleles. Following this, conditional logistic regression is used to assess the significance of the main and interaction terms. Since transmission to multiple affected siblings cannot be assumed to be independent events, and since the families in our sample may contain more than one case, robust estimates for the variance and Wald tests were used instead of likelihood ratio tests for the SLSJ, CAPPS and SAGE studies. Considering the number of SNPs genotyped in genes involved in the vitamin D pathway, a total of 5003 two-gene interaction models were evaluated.

Post hoc analyses were performed with the combined dataset (SLSJ, CAPPS, SAGE, and BHS). Tests of association were performed using the likelihood method implemented in UNPHASE v3.0.10 [44], which allow data from family studies and case-control individuals to be analyzed together.

\section{Results \\ Results from the SLSJ population}

Additional file 1 presents the 87 genotyped SNPs and their characteristics in the SLSJ study. Two SNPs failed the assay design including one in the CD86 gene (rs1915087) and another in the GC gene (rs1491711). Both of these SNPs are singletons and are not tagging other SNPs in the genes. A third SNP (rs8176353) located in the CYP27B1 gene was monomorphic. Additional file 1 also showed the minor allele frequencies for a reference population (CEPH from HapMap) and for the SLSJ study. In most cases, the minor allele frequencies were very similar between the two populations with a mean difference of $2 \%$ and the largest difference was $16 \%$ for SNP rs 4308217 located in the CD86 gene. After Bonferroni correction, only one SNP was out of Hardy-Weinberg equilibrium (see Additional file 1). This SNP (rs4809960) is a singleton in the CYP24A1 gene and was removed from further analyses. Accordingly, a total of 83 SNPs were tested for association with asthma and atopy. Additional file 2 shows the exon-intron structure of each gene and the location of genotyped SNPs.

The overall distribution of single marker FBAT association tests shows a greater number of small $p$ values for asthma compared to what was expected by chance (see Additional file 3). Results for genes with at least one significant $\mathrm{p}$ value for asthma and atopy are illustrated in Figure 2 (results for all genes are illustrated in Additional file 2). The details of these tests are shown in Table 2 for SNPs having at least one $\mathrm{p}$ value $<0.1$ for asthma or atopy (FBAT results for all SNPs can be found in Additional file $4)$. Five SNPs in the IL10 gene, three located in the promoter (rs1800872, rs1800871, rs1800896), one in intron 1 (rs3024490), and the other located in the 3' region (rs4844553) were significantly associated with asthma. Three of them (rs1800871, rs1800872, and rs3024490) were in tight $\operatorname{LD}\left(\mathrm{r}^{2}>0.97\right)$, while the others were in low to modest LD (Figure 3). Haplotype analysis for the three tightly linked SNPs revealed the presence of only two haplotypes with an allele frequency above $1 \%$ in the SLSJ population. The TAA haplotype had a frequency of 0.268 and was overtransmitted to asthma patients $(\mathrm{p}=0.024)$, while the CCC haplotype had a frequency of 0.726 and was undertransmitted $(\mathrm{p}=0.013)$. Four out of the eight genotyped SNPs in the CYP24A1 gene were also modestly associated with asthma or atopy (range of $\mathrm{p}$ values $=0.051$ to $0.015)$. The two intronic SNPs associated with atopy (rs912505 and rs927650) were in modest LD $\left(r^{2}=0.36\right)$ and the two SNPs associated with asthma (rs2248359 and rs8124792) located in the promoter and the 3' region of the gene were in complete equilibrium $\left(\mathrm{r}^{2}=0\right)$ (Figure 3$)$. Three intronic SNPs in the IL1RL1 gene were also associated with asthma. Two of them (rs1420089 and rs 1861245$)$ were in modest $\operatorname{LD}\left(\mathrm{r}^{2}=0.28\right)$ and the third 
Table 2: Single SNP association results for asthma and atopy in the Saguenay-Lac-Saint-Jean study.

\begin{tabular}{|c|c|c|c|c|c|c|c|c|c|c|}
\hline \multirow[b]{2}{*}{ Gene } & \multirow[b]{2}{*}{ SNP } & \multicolumn{5}{|c|}{ Asthma } & \multicolumn{4}{|c|}{ Atopy } \\
\hline & & Allele & Allele frequency & \# of families* & $\mathbf{Z}$ & $P$ value & Allele frequency & \# of families* & $\mathbf{Z}$ & $P$ value \\
\hline \multirow[t]{10}{*}{ ILIO } & rs4844553 & $\mathrm{C}$ & 0.94 & 39 & 2.10 & 0.036 & 0.94 & 33 & 0.15 & 0.881 \\
\hline & & $\mathrm{T}$ & 0.06 & 39 & -2.10 & 0.036 & 0.06 & 33 & -0.15 & 0.881 \\
\hline & rs3024490 & A & 0.28 & 105 & 2.42 & 0.016 & 0.28 & 94 & 0.80 & 0.423 \\
\hline & & $\mathrm{C}$ & 0.72 & 105 & -2.42 & 0.016 & 0.72 & 94 & -0.80 & 0.423 \\
\hline & rs|800872 & A & 0.28 & 105 & 2.42 & 0.016 & 0.28 & 94 & 0.80 & 0.423 \\
\hline & & C & 0.72 & 105 & -2.42 & 0.016 & 0.72 & 94 & -0.80 & 0.423 \\
\hline & rs|80087| & $\mathrm{C}$ & 0.71 & 95 & -2.52 & 0.012 & 0.71 & 84 & -1.22 & 0.221 \\
\hline & & $\mathrm{T}$ & 0.29 & 95 & 2.52 & 0.012 & 0.29 & 84 & 1.22 & 0.221 \\
\hline & rs|800896 & C & 0.46 & 117 & -2.47 & 0.014 & 0.46 & 101 & -1.49 & 0.137 \\
\hline & & $\mathrm{T}$ & 0.54 & 117 & 2.47 & 0.014 & 0.54 & 101 & 1.49 & 0.137 \\
\hline \multirow[t]{10}{*}{ ILIRLI } & rs 950880 & A & 0.39 & 126 & 1.73 & 0.084 & 0.39 & 105 & 1.64 & 0.100 \\
\hline & & C & 0.61 & 126 & -1.73 & 0.084 & 0.61 & 105 & -1.64 & 0.100 \\
\hline & rs|420089 & C & 0.18 & 72 & -2.14 & 0.033 & 0.18 & 60 & -0.21 & 0.832 \\
\hline & & $\mathrm{T}$ & 0.82 & 72 & 2.14 & 0.033 & 0.82 & 60 & 0.21 & 0.832 \\
\hline & rs1946131 & C & 0.92 & 53 & -2.44 & 0.015 & 0.92 & 42 & -1.96 & 0.050 \\
\hline & & $T$ & 0.09 & 53 & 2.44 & 0.015 & 0.09 & 42 & 1.96 & 0.050 \\
\hline & rs1921622 & C & 0.54 & 75 & -1.65 & 0.099 & 0.54 & 65 & -1.39 & 0.165 \\
\hline & & $\mathrm{T}$ & 0.46 & 75 & 1.65 & 0.099 & 0.46 & 65 & 1.39 & 0.165 \\
\hline & rs|86|245 & A & 0.43 & 101 & -2.14 & 0.032 & 0.43 & 74 & -1.19 & 0.235 \\
\hline & & G & 0.57 & 101 & 2.14 & 0.032 & 0.57 & 74 & 1.19 & 0.235 \\
\hline \multirow[t]{2}{*}{$C D 28$} & rs6435203 & C & 0.34 & 120 & -1.97 & 0.049 & 0.34 & 104 & -1.17 & 0.243 \\
\hline & & $\mathrm{T}$ & 0.67 & 120 & 1.97 & 0.049 & 0.67 & 104 & 1.17 & 0.243 \\
\hline \multirow[t]{2}{*}{ CYP27AI } & rs4674338 & C & 0.60 & 96 & 1.85 & 0.064 & 0.60 & 82 & 1.72 & 0.085 \\
\hline & & $\mathrm{T}$ & $0.4 I$ & 96 & -1.85 & 0.064 & 0.41 & 82 & -1.72 & 0.085 \\
\hline \multirow[t]{8}{*}{ CD86 } & rs27I5267 & A & 0.64 & 102 & -1.82 & 0.069 & 0.64 & 91 & -2.86 & 0.004 \\
\hline & & C & 0.37 & 102 & 1.82 & 0.069 & 0.37 & 91 & 2.86 & 0.004 \\
\hline & rs27I5273 & A & 0.82 & 79 & 1.75 & 0.081 & 0.82 & 65 & 1.67 & 0.096 \\
\hline & & $\mathrm{T}$ & 0.18 & 79 & -1.75 & 0.081 & 0.18 & 65 & -1.67 & 0.096 \\
\hline & rs6805035 & A & 0.88 & 51 & 1.74 & 0.083 & 0.88 & 43 & 1.43 & 0.154 \\
\hline & & C & 0.12 & 51 & -1.74 & 0.083 & 0.12 & 43 & -1.43 & 0.154 \\
\hline & rs2332096 & A & 0.46 & 117 & -1.39 & 0.164 & 0.46 & 108 & -1.79 & 0.074 \\
\hline & & C & 0.54 & 117 & 1.39 & 0.164 & 0.54 & 108 & 1.79 & 0.074 \\
\hline \multirow[t]{2}{*}{ CYP2RI } & rsII023374 & C & 0.33 & 105 & 2.38 & 0.017 & 0.33 & 88 & 1.33 & 0.183 \\
\hline & & $\mathrm{T}$ & 0.67 & 105 & -2.38 & 0.017 & 0.67 & 88 & -1.33 & 0.183 \\
\hline \multirow[t]{8}{*}{ CYP24AI } & rs8I24792 & C & 0.95 & 22 & 2.18 & 0.030 & 0.95 & 24 & 1.89 & 0.058 \\
\hline & & $\mathrm{T}$ & 0.05 & 22 & -2.18 & 0.030 & 0.05 & 24 & -1.89 & 0.058 \\
\hline & rs 927650 & C & 0.55 & 108 & -1.65 & 0.100 & 0.55 & 91 & -1.95 & 0.051 \\
\hline & & $\mathrm{T}$ & 0.45 & 108 & 1.65 & 0.100 & 0.45 & 91 & 1.95 & 0.051 \\
\hline & rs912505 & C & 0.29 & 89 & -1.63 & 0.104 & 0.29 & 80 & -2.44 & 0.015 \\
\hline & & $T$ & 0.71 & 89 & 1.63 & 0.104 & 0.71 & 80 & 2.44 & 0.015 \\
\hline & rs2248359 & C & 0.58 & 112 & 2.15 & 0.032 & 0.58 & 97 & 0.56 & 0.577 \\
\hline & & $\mathrm{T}$ & 0.42 & 112 & -2.15 & 0.032 & 0.42 & 97 & -0.56 & 0.577 \\
\hline
\end{tabular}

*Number of informative families to conduct the test.

$P$ values $<0.05$ are shown in bold. 


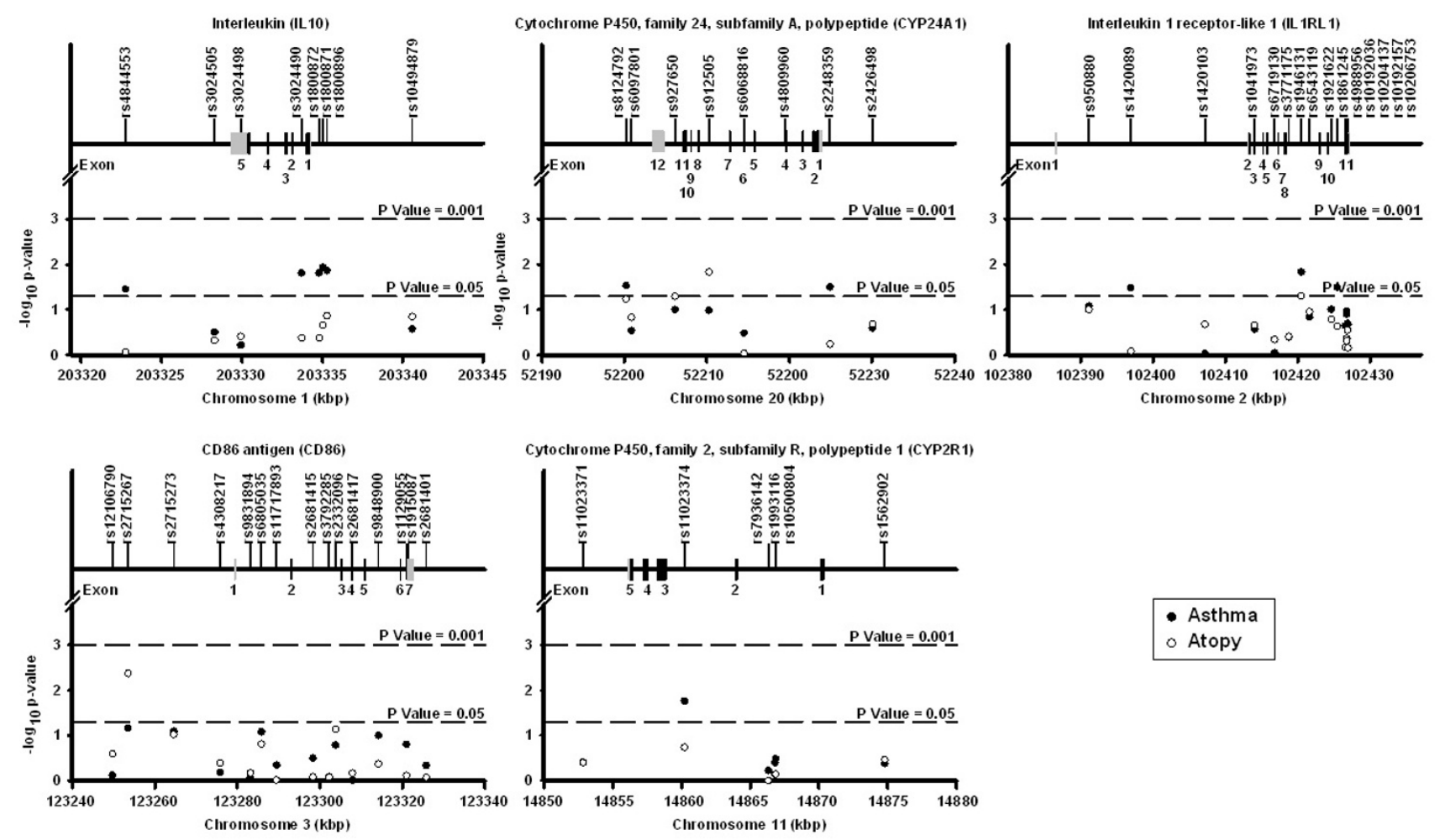

Figure 2

Genetic association of SNPs in the vitamin D pathway genes with asthma and atopy in the SLSJ study. Only genes with a least one significant $p$ value $(p<0.05)$ are illustrated. Each subfigure presents the result of one gene. The top line indicates the gene name and symbol. The upper part of each subfigure shows the exon-intron structure of the gene and the localization of the genotyped SNPs. The coding exons are shown in black and the untranslated regions are shown in grey. The lower part of each subfigure illustrates the association results for asthma (solid circles) and atopy (open circles). The $x$-axis shows the localization of the gene and SNPs on NCBI Human Genome build 35. The y-axis shows the FBAT empirical $p$ values on a $\log _{10}$ scale. The lower and upper dashed lines represent $p$ value thresholds of 0.05 and 0.001 , respectively. The upper and lower parts of each subfigure are shown on the same scale.

one (rs1946131) showed no LD with the other (Figure 3). Also worth mentioning is a SNP (rs2715267) in the promoter region of the CD86 gene that was significantly associated with atopy $(\mathrm{p}=0.004)$. A trend for this SNP was also observed for asthma ( $\mathrm{p}=0.069)$. Finally, one SNP (rs11023374) in intron 2 of the CYP2R1 gene was associated with asthma $(\mathrm{p}=0.017)$. LD plots for all genes are illustrated in Additional file 5.

Interaction among functionally related genes may not be surprising. Hence, all possible two-gene interactions were tested for asthma in the SLSJ study for the 11 genes under study plus the VDR gene (Figure 4). Two concentrated spots of significant two-gene models for asthma are observed in this figure. The one at the bottom represents two-gene models involving SNPs in the IL10 and VDR genes. The second spot located in the center of Figure 4 represents two-gene models involving SNPs in the IL10 and IL1RL1 genes. Multiple two-gene models were also significant between SNPs in the IL10 and CD86 genes. Additional file 6 shows the two-gene models for atopy in the SLSJ study. Overall, gene-gene interactions were modest for atopy.

To understand the impact of these two-gene models on the risk of asthma, the genotype by genotype odds ratio matrix was calculated and some representative and most significant two-gene models are illustrated in Figure 5. Figure $5 \mathrm{a}, \mathrm{b}$ and $5 \mathrm{c}$ show two-gene models between SNPs in the IL10 and VDR genes. Figure 5a shows that the risk of having asthma is similar for carriers of two rare IL10 alleles irrespective of the VDR genotypes. However, the risk increases with the increasing number of common IL10 alleles for individuals who are homozygous for the common VDR allele. In contrast, the risk tends to decrease with the increasing number of common IL10 alleles for individuals who are homozygous for the rare VDR allele. Figure 5b shows that the risk of asthma increases with the 

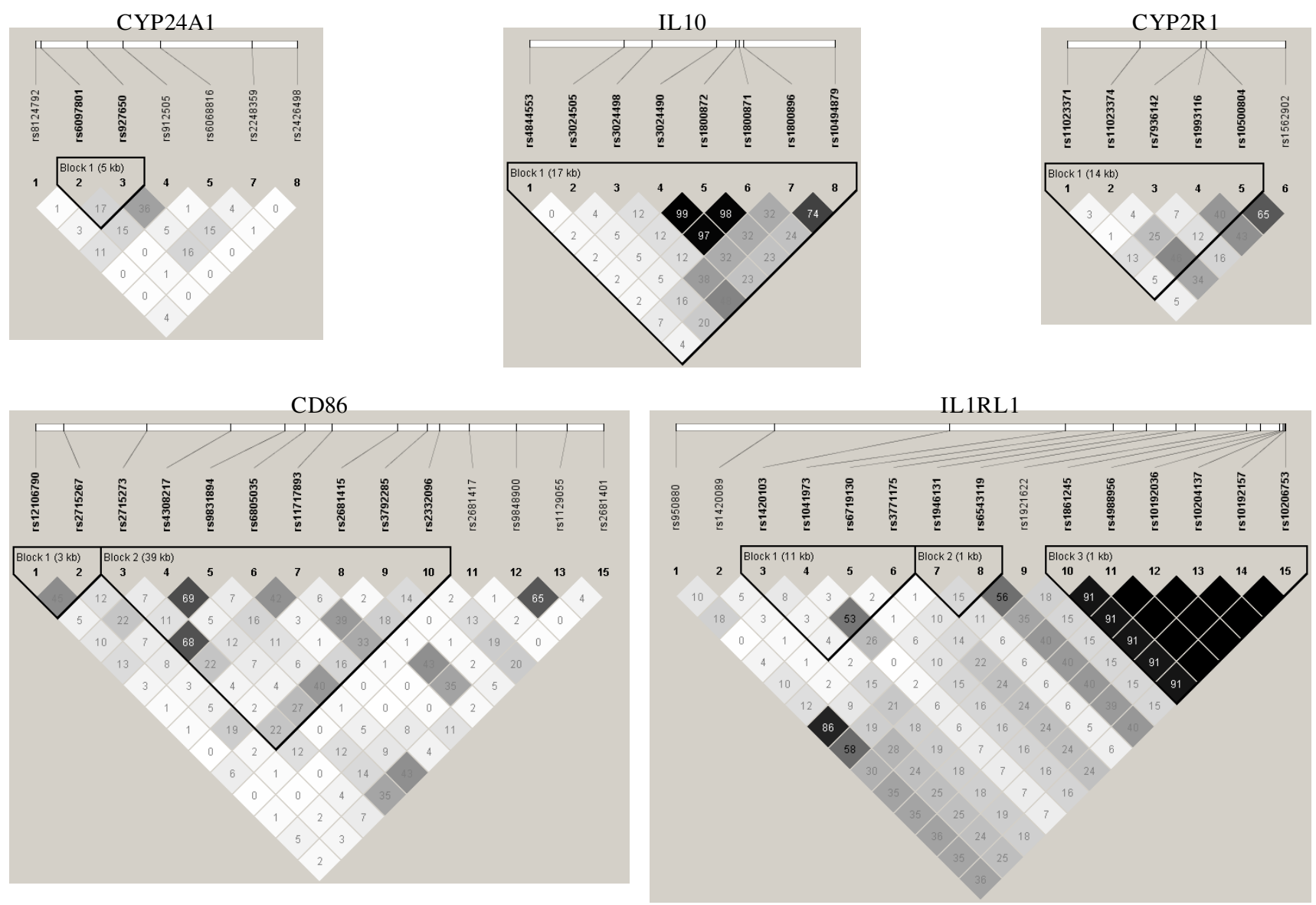

Figure 3

Linkage disequilibrium (LD) plots surrounding five genes involved in the vitamin D pathway in the SLSJ study. The LD plots were generated by Haploview 3.32 [4I]. Gene symbols are indicated at the top of each graph. The top horizontal bar illustrates the location of SNPs on a physical scale. The color of squares illustrates the strength of pairwise $r^{2}$ values on a black and white scale where black indicates perfect LD $\left(r^{2}=1.00\right)$ and white indicates perfect equilibrium $\left(r^{2}=0\right)$. The $r^{2}$ LD value is also indicated within each square. Blocks are defined using the Gabriel et al [7I] definition. Failed and monomorphic SNPs as well as SNPs not in Hardy-Weinberg equilibrium are not illustrated.

number of rare IL10 alleles, but the effect is greater with an increasing number of common alleles at the VDR locus. Figure 5a and 5b show representative interactions between SNPs located in the promoter region of IL10 and the 3'UTR region of $V D R$. However, more complex interactions between these two genes were observed between SNPs located in the 3'UTR region of both genes. Figure 5c shows that the effect of the IL10 rare allele goes in the opposite directions depending on whether subjects are homozygous for the common or the rare VDR alleles. Figure $5 \mathrm{~d}$ shows a representative interaction between promoter polymorphisms in the IL10 gene and nonsynonymous SNPs located in the IL1RL1 gene. In this model, the rare IL10 alleles increase the risk, but the magnitude of the effect is greater with the number of rare alleles at the IL1RL1 gene. Figure 5e shows a representative interaction between promoter polymorphisms in the IL10 and CD86 genes. In this model, the risk of asthma is similar for carriers of two common CD86 alleles irrespective of the IL10 genotypes, however, the risk increases additively with the number of rare alleles in the two genes.

\section{Replication samples}

For all the single SNP associations observed in the SLSJ population, the statistical significance was modest and did not survive multiple correction procedures. Accordingly, an effort was made to replicate these findings in three additional studies. A comprehensive set of tagging SNPs in the IL10, CYP24A1, IL1RL1, CD86, and CYP2R1 genes plus the significant $(\mathrm{p}<0.05)$ SNPs in the SLSJ study were genotyped in the CAPPS, SAGE and BHS studies. Table 3 shows SNPs with at least one p value $<0.05$ for asthma or atopy in the three studies as well as SNPs with $\mathrm{p}$ value $<0.05$ in the SLSJ study. Complete results for the 


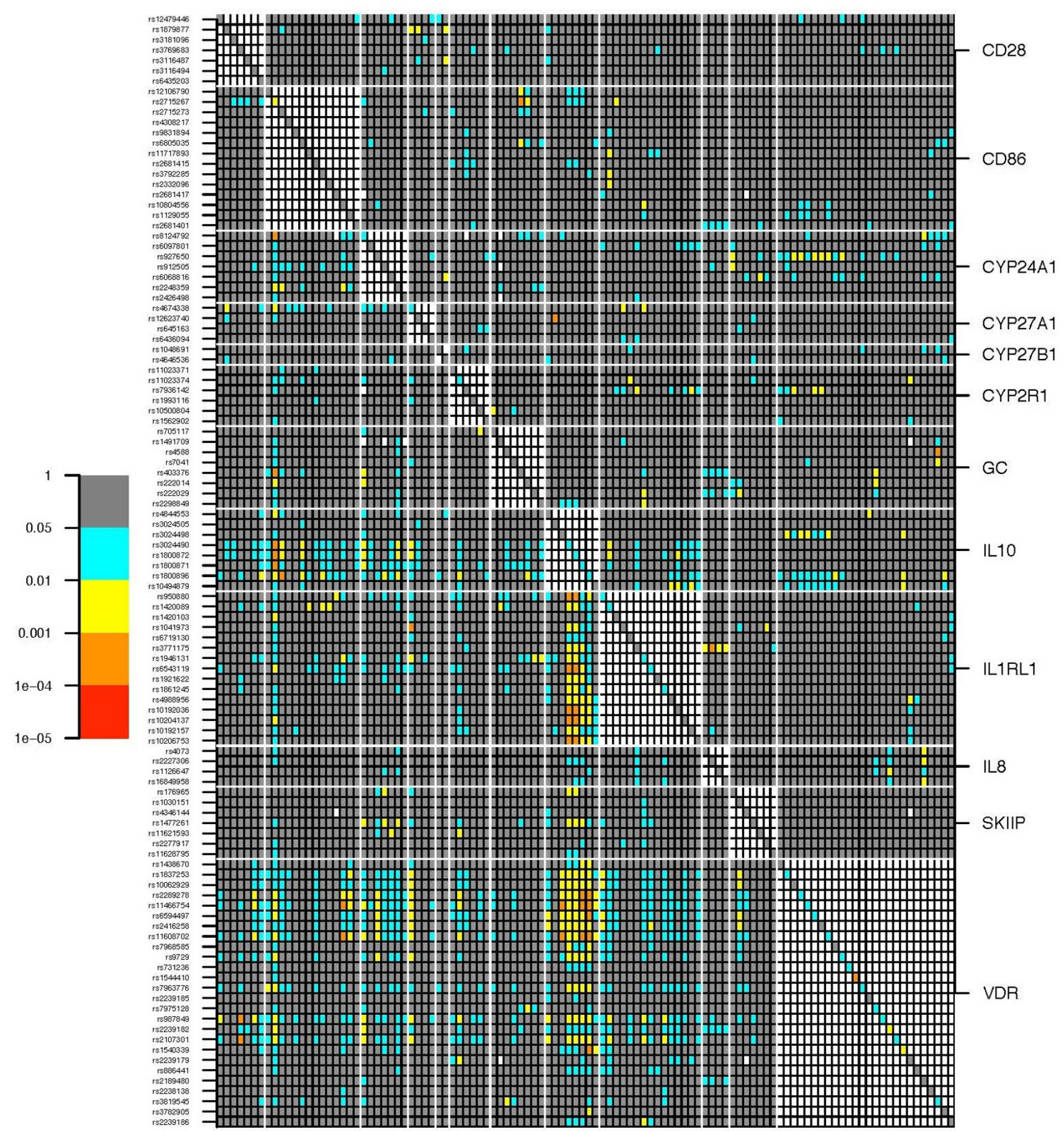

Figure 4 (see legend on next page) 
Figure 4 (see previous page)

Two-gene model analyses on asthma in the SLSJ study for genes involved in the vitamin D pathway. The plot illustrates the $p$ values for single SNP association and all possible two-SNP combinations. Each line represents a SNP listed at the left of the figure. Each column represents a SNP listed in the same order but from left to right. The white horizontal and vertical lines break up the figure by genes. Gene names are indicated at the right of the figure. $P$ values are illustrated using the following color scheme: grey, $p>0.05$; blue, $0.05>p>0.0$ I; yellow, $0.01>p>0.00$ I; orange, $0.001>p>0.000$ I, red, 0.000 I $>p>0.0000$ l. The squares forming the diagonal (upper-left to lower-right) depict $p$ values for single SNP association based on a Wald test (see materials and methods). Two-gene models for SNPs located in the same gene were not assessed and were not coloured, which created the large white square patterns along the diagonal. Illustrated above the diagonal are $p$ values for the interaction term only, which are the results of Wald tests contrasting the full model (two main effects and the interaction) to the reduced model (two main effects only). Illustrated below the diagonal are $p$ values testing the full model (two main effects and the interaction) against a reduced model that is conditional on single SNPs declared significant when taken individually, if any (see materials and methods). White squares illustrate tests for which the model failed to converge.

replicate samples can be found in Additional file 7. For IL10, none of the SNPs associated with asthma in the SLSJ study were significant in the other studies except the promoter polymorphism rs 1800896 , with a marginal $\mathrm{p}$ value of 0.022 in CAPPS. However, the $\mathrm{C}$ allele that was protective in the SLSJ study was the risk allele in the CAPPS study. The direction of the risk allele in the SAGE study was similar to the one observed in the SLSJ, but the effect was not significant. Similar flip-flop phenomena were observed between the SAGE and CAPPS studies for SNPs that were not significant in the SLSJ study. Two SNPs in tight LD, rs3024498 located in the 3'UTR and rs3024492 located in intron 3 , showed p values $>0.01$ in both replicate samples, but the orientation of the risk allele was reversed. For most IL10 SNPs, it was noticeable that the orientation of the risk alleles is in agreement between the SLSJ and SAGE studies and in the opposite direction for CAPPS. No SNP in the IL10 gene was significantly associated with asthma or atopy in the BHS. Taken together, significant associations in the IL10 gene were observed in three studies. However, different SNPs were associated in different populations and the direction of the risk allele in the CAPPS study was reversed compared with the SLSJ and SAGE studies.

The associations observed for the IL1RL1 and CYP2R1 genes in the SLSJ study were not validated in the replication samples (Table 3). No other SNP in the IL1RL1 gene was associated with asthma or atopy in the replication studies except a non-synonymous coding SNP (rs1041973, Glu78Ala) that was borderline significant for atopy in SAGE. For CYP2R1, two additional SNPs located in the promoter and intron 1 were associated with asthma in the BHS. However, none of these SNPs were replicated in the other studies. For CD86, the promoter SNP (rs2715267) that was associated with atopy in the SLSJ (p $=0.004$ ) could not be assessed in the other studies due to failure of the genotyping assay. However, two other intronic SNPs (rs9831894 and rs2332096, $\mathrm{r}^{2}=0.48$ in the European HapMap data), not in LD with rs2715267, were significantly associated with asthma in CAPPS. A different SNP (rs9282641) located in non-coding exon 1 was significantly associated with asthma in the BHS. This latter SNP was not in LD with any of the three SNPs associated with asthma in CAPPS and SLSJ. Accordingly, different CD86 polymorphims were associated with asthma in three populations. Finally, significant SNPs were observed in the CYP24A1 gene in all studies. However, there was no consistency with the SLSJ study in terms of phenotype and orientation of the risk alleles.

The two-gene models were also performed in the replication samples for the five genes that were genotyped in CAMP, SAGE and BHS. The significant two-gene models involving IL10 and VDR as well as IL10 and IL1RL1 observed in the SLSJ study is not replicated in the CAPPS, SAGE and BHS. It should be noted that the sample sizes in the SAGE and CAPPS studies limit our ability to replicate the findings. For example, the number of cases contributing to the two-gene model involving IL10rs1800896 and VDR-rs1544410 (Figure 5a) was approximately halved in SAGE and reduced to a quarter in CAPPS compared with the SLSJ study. However, even with similar power, the significant two-gene models observed in the SLSJ are not replicated in the BHS (see Additional file 8). Taken together, none of the significant two-gene models observed in the SLSJ study were properly replicated in CAPPS, SAGE and BHS.

The significant two-gene models involving IL10 and VDR were also tested in the CAMP study. A different panel of SNPs was genotyped in CAMP and some of the two-gene models are significant $(\mathrm{p}<0.05)$. The most significant two-gene models is observed between VDR-rs7975232 and IL10-rs1800896 (Wald test $\mathrm{p}=0.018$ ) or IL10rs 1800872 (Wald-test $p=0.016$ ). Figure 6 shows the comparison of two-gene models observed in the SLSJ and CAMP studies. VDR-rs1544410 is not genotyped in CAMP, but rs7975232 was in moderately high LD with it $\left(D^{\prime}=1.0\right.$ and $r^{2}=0.59$, based on the HapMap CEU geno- 

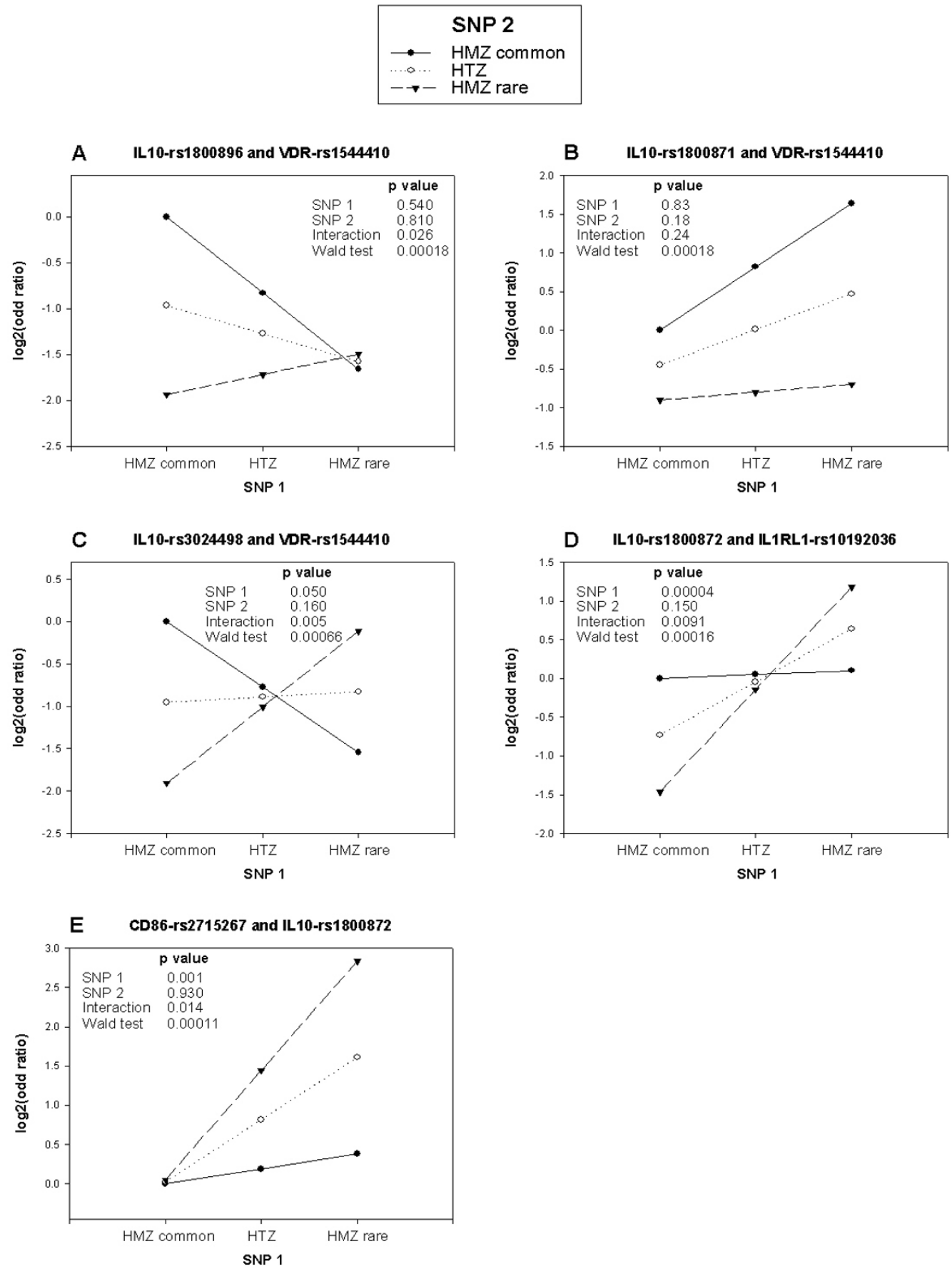

Figure 5

Combined genotypic effects of selected two-gene models on asthma in the SLSJ study. Each subfigure illustrates the risk of asthma according to two SNPs located in different genes. The genes and SNPs named are indicated above each subfigure representing SNP I and SNP 2, respectively. With two bi-allelic SNPs (3 genotypes per SNP), a 3 by 3 odds ratio matrix is calculated and visually represented. All risks are evaluated relative to homozygotes for the common allele at both SNPs. The $y$-axis shows the odds ratio on a $\log _{2}$ scale, which makes the odds ratio above and below I on the same visual scale. The $x$-axis indicates the genotypes for SNP number I. By drawing a line that joins the dots representing the genotypes for SNP number 2, the genotypic effect of SNP number I can be observed on different genotypic backgrounds of SNP number 2 . The first three $P$ values come from a model testing the main effect of both SNPs and the interaction term. The Wald test $p$ value is the result of the full two-gene model tested against a reduced model (see materials and methods). 


\begin{tabular}{|c|c|c|c|c|c|c|c|c|c|c|c|c|c|c|c|c|c|c|c|c|c|c|c|c|c|c|}
\hline \multirow[b]{3}{*}{ Genes } & \multirow[b]{3}{*}{ SNPs } & \multirow[b]{3}{*}{ Allele } & \multicolumn{12}{|c|}{ Asthma } & \multicolumn{12}{|c|}{ Atopy } \\
\hline & & & \multicolumn{4}{|c|}{ SAGE } & \multicolumn{4}{|c|}{ CAPPS } & \multicolumn{4}{|c|}{ BHS } & \multicolumn{4}{|c|}{ SAGE } & \multicolumn{4}{|c|}{ CAPPS } & \multicolumn{4}{|c|}{ BHS } \\
\hline & & & $\mathbf{A F}$ & $\mathbf{F a}$ & $\mathbf{z}$ & $\mathbf{p}$ & $\mathbf{A F}$ & $\mathbf{F a}$ & $\mathbf{z}$ & $\mathbf{p}$ & $\begin{array}{l}\text { AF } \\
\text { case }\end{array}$ & $\begin{array}{l}\text { AF } \\
\text { ctrl }\end{array}$ & $\mathbf{x}^{2}$ & $\mathbf{p}$ & $\mathbf{A F}$ & $\mathbf{F a}$ & $\mathbf{z}$ & $\mathbf{p}$ & $\mathbf{A F}$ & $\mathbf{F a}$ & $\mathbf{z}$ & $\mathbf{p}$ & $\begin{array}{l}\text { AF } \\
\text { case }\end{array}$ & $\begin{array}{l}\text { AF } \\
\text { ctrl }\end{array}$ & $\mathbf{X}^{2}$ & $\mathbf{p}$ \\
\hline \multirow[t]{14}{*}{ ILIO } & $\underline{\mathrm{rs} 4844553}$ & A & 0.07 & 25 & 0.96 & 0.336 & 0.05 & 11 & 0.3 & 0.763 & 0.05 & 0.06 & 1.21 & 0.272 & 0.07 & 35 & -0.16 & 0.873 & 0.05 & 22 & -1.88 & 0.061 & 0.05 & 0.06 & 0.12 & 0.729 \\
\hline & & $\underline{G}$ & 0.93 & 25 & -0.96 & 0.336 & 0.95 & 11 & -0.3 & 0.763 & & & & & 0.93 & 35 & 0.16 & 0.873 & 0.95 & 22 & 1.88 & 0.061 & & & & \\
\hline & rs3024498 & A & 0.78 & 83 & 3.06 & 0.002 & 0.78 & 40 & -2.56 & 0.01 & 0.70 & 0.72 & 1.74 & 0.187 & 0.78 & 108 & 1.22 & 0.223 & 0.78 & 70 & -0.54 & 0.592 & 0.71 & 0.72 & 0.26 & 0.608 \\
\hline & & G & 0.23 & 83 & -3.06 & 0.002 & 0.22 & 40 & 2.56 & 0.01 & & & & & 0.23 & 108 & -1.22 & 0.223 & 0.22 & 70 & 0.54 & 0.592 & & & & \\
\hline & rs3024492 & A & 0.78 & 81 & 2.89 & 0.004 & 0.78 & 40 & -2.56 & 0.01 & 0.70 & 0.72 & 1.55 & 0.213 & 0.78 & 108 & 1.13 & 0.26 & 0.78 & 69 & -0.75 & 0.453 & 0.71 & 0.72 & 0.20 & 0.655 \\
\hline & & $\mathrm{T}$ & 0.22 & 81 & -2.89 & 0.004 & 0.22 & 40 & 2.56 & 0.01 & & & & & 0.22 & 108 & -1.13 & 0.26 & 0.22 & 69 & 0.75 & 0.453 & & & & \\
\hline & $\underline{\mathrm{rs} 3024490}$ & $\underline{A}$ & 0.28 & 69 & 0.63 & 0.527 & 0.29 & 34 & -1.64 & 0.101 & 0.24 & 0.22 & 1.63 & 0.202 & 0.28 & 99 & 0.36 & 0.717 & 0.29 & 78 & 0 & 1 & 0.23 & 0.23 & 0.07 & 0.788 \\
\hline & & C & 0.72 & 69 & -0.63 & 0.527 & 0.71 & 34 & 1.64 & 0.101 & & & & & 0.72 & 99 & -0.36 & 0.717 & 0.71 & 78 & 0 & I & & & & \\
\hline & rs 1800872 & $\underline{A}$ & 0.28 & 70 & 0.73 & 0.463 & 0.3 & 34 & -1.64 & 0.101 & 0.24 & 0.22 & 1.64 & 0.200 & 0.28 & 98 & 0.46 & 0.649 & 0.3 & 78 & -0.1 & 0.922 & 0.23 & 0.23 & 0.07 & 0.786 \\
\hline & & C & 0.72 & 70 & -0.73 & 0.463 & 0.7 & 34 & 1.64 & 0.101 & & & & & 0.72 & 98 & -0.46 & 0.649 & 0.7 & 78 & 0.1 & 0.922 & & & & \\
\hline & $\underline{\mathrm{rs}} 1800896$ & C & 0.43 & 87 & -1.22 & 0.221 & 0.43 & 40 & 2.29 & 0.022 & 0.50 & 0.50 & 0.02 & 0.889 & 0.43 & 124 & -0.55 & 0.583 & 0.43 & 83 & 0.29 & 0.772 & 0.50 & 0.50 & 0.06 & 0.804 \\
\hline & & $I$ & 0.57 & 87 & 1.22 & 0.221 & 0.58 & 40 & -2.29 & 0.022 & & & & & 0.57 & 124 & 0.55 & 0.583 & 0.58 & 83 & -0.29 & 0.772 & & & & \\
\hline & rs 10494879 & C & 0.63 & 93 & 1.44 & 0.151 & 0.64 & 42 & -2.07 & 0.039 & 0.55 & 0.56 & 0.51 & 0.476 & 0.63 & 127 & 0.08 & 0.938 & 0.64 & 82 & -1.18 & 0.239 & 0.55 & 0.56 & 0.13 & 0.717 \\
\hline & & G & 0.37 & 93 & -1.44 & 0.151 & 0.36 & 42 & 2.07 & 0.039 & & & & & 0.37 & 127 & -0.08 & 0.938 & 0.36 & 82 & 1.18 & 0.239 & & & & \\
\hline \multirow[t]{6}{*}{ ILIRLI } & $\underline{\mathrm{rs}} \mid 420089$ & C & 0.09 & 39 & 1.41 & 0.16 & 0.09 & 19 & -0.23 & 0.819 & 0.11 & 0.11 & 0.08 & 0.782 & 0.09 & 50 & 1.91 & 0.057 & 0.09 & 40 & 0 & I & 0.12 & 0.12 & 0.03 & 0.874 \\
\hline & & I & 0.91 & 39 & $-1.4 \mid$ & 0.16 & 0.91 & 19 & 0.23 & 0.819 & & & & & 0.91 & 50 & -1.91 & 0.057 & 0.91 & 40 & 0 & 1 & & & & \\
\hline & rs1041973 & A & 0.22 & 80 & -0.1 & 0.921 & 0.23 & 35 & 0.16 & 0.876 & & & & & 0.22 & 98 & -1.99 & 0.046 & 0.23 & 73 & 0.11 & 0.915 & & & & \\
\hline & & C & 0.78 & 80 & 0.1 & 0.921 & 0.77 & 35 & -0.16 & 0.876 & & & & & 0.78 & 98 & 1.99 & 0.046 & 0.77 & 73 & -0.11 & 0.915 & & & & \\
\hline & $\underline{\mathrm{rs}|946| 3 \mid}$ & $\underline{A}$ & 0.11 & 43 & -0.3 & 0.768 & 0.1 & 16 & -0.23 & 0.819 & 0.10 & 0.10 & 0.36 & 0.55 & 0.11 & 52 & -1.05 & 0.294 & 0.1 & 37 & 0.78 & 0.435 & 0.10 & 0.09 & 1.61 & 0.205 \\
\hline & & G & 0.9 & 43 & 0.3 & 0.768 & 0.9 & 16 & 0.23 & 0.819 & & & & & 0.9 & 52 & 1.05 & 0.294 & 0.9 & 37 & -0.78 & 0.435 & & & & \\
\hline \multirow[t]{4}{*}{ CD86 } & rs928264I & C & 0.93 & 36 & 0.8 & 0.423 & 0.93 & 14 & -0.78 & 0.439 & 0.89 & 0.92 & 7.34 & 0.007 & 0.93 & 42 & 0 & I & 0.93 & 35 & -0.16 & 0.873 & 0.91 & 0.90 & 0.82 & 0.365 \\
\hline & & $\mathrm{T}$ & 0.07 & 36 & -0.8 & 0.423 & 0.07 & 14 & 0.78 & 0.439 & & & & & 0.07 & 42 & 0 & 1 & 0.07 & 35 & 0.16 & 0.873 & & & & \\
\hline & rs9831894 & G & 0.42 & 88 & -1.12 & 0.261 & 0.4 & 40 & -2.61 & 0.009 & 0.39 & 0.39 & 0.00 & 0.952 & 0.42 & 124 & -0.23 & 0.817 & 0.4 & 96 & -0.26 & 0.792 & 0.39 & 0.40 & 0.21 & 0.645 \\
\hline & & $\mathrm{T}$ & 0.58 & 88 & 1.12 & 0.261 & 0.6 & 40 & 2.61 & 0.009 & & & & & 0.58 & 124 & 0.23 & 0.817 & 0.6 & 96 & 0.26 & 0.792 & & & & \\
\hline
\end{tabular}


o Table 3: Single SNP association results for asthma and atopy in the replication samples. (Continued)

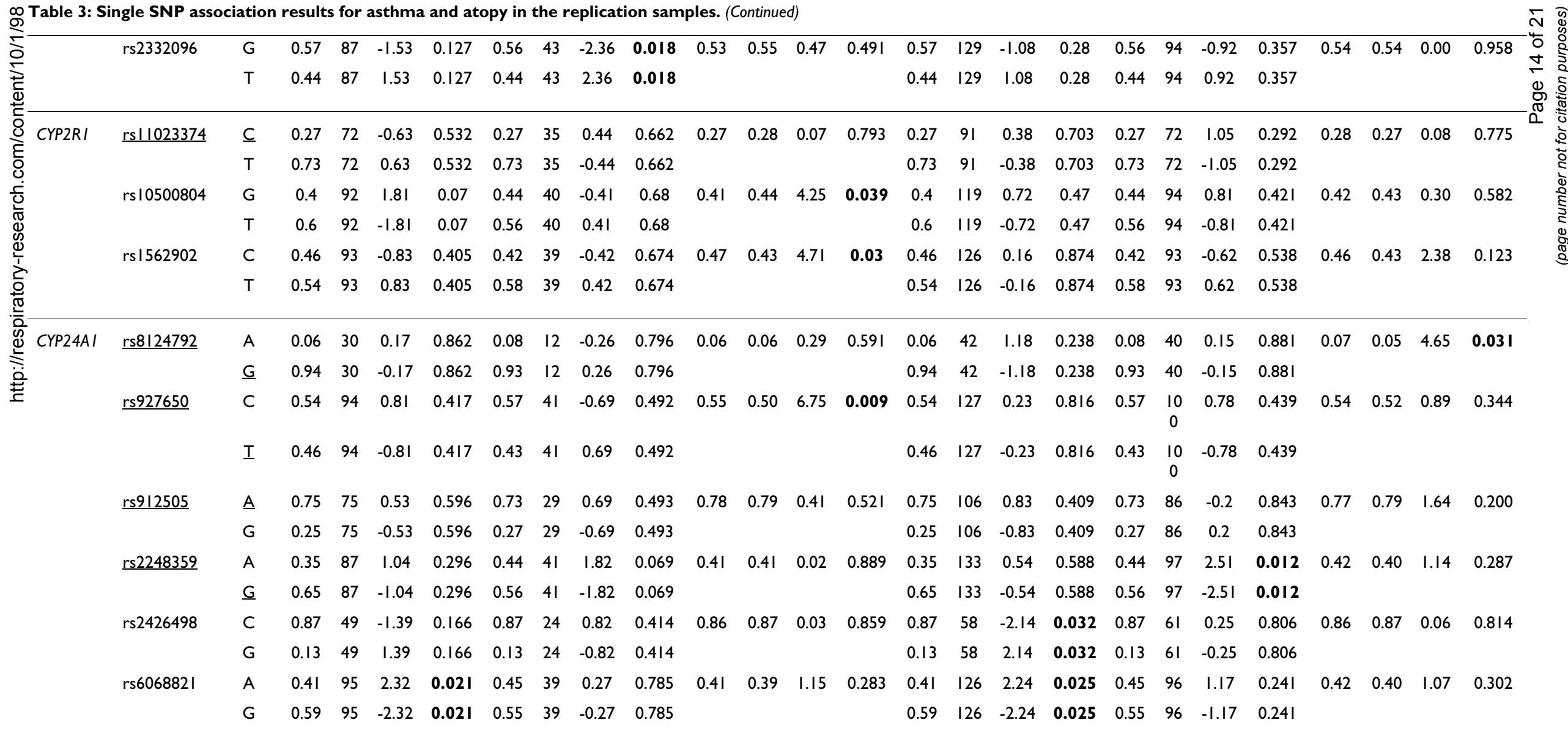

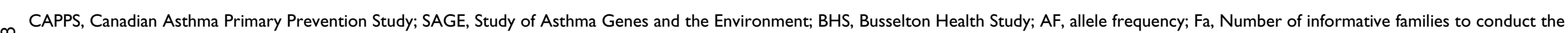
$\infty$ test.

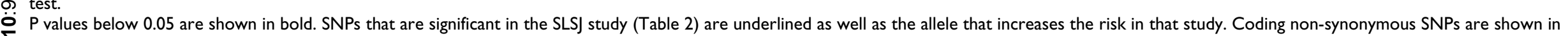
के bold. 

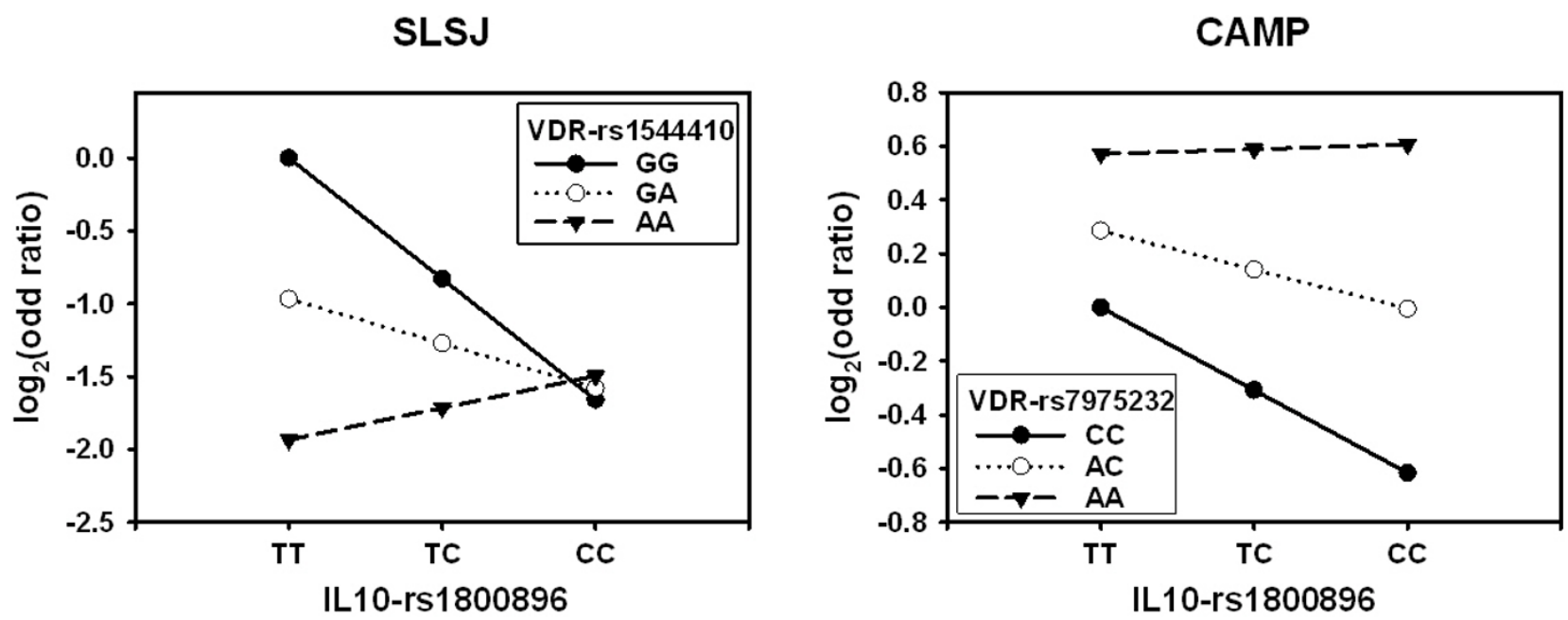

Figure 6

Two-gene models on asthma involving the ILIO and VDR genes in the SLSJ and the CAMP studies. With two biallelic SNPs (3 genotypes per SNP), a 3 by 3 odds ratio matrix is calculated and visually represented. The $y$-axis shows the odds ratio on a $\log _{2}$ scale, which makes the odds ratio above and below I on the same visual scale. The IL I 0 genotypes are illustrated on the x-axis. Different panels of SNPs were genotyped between the two studies and the comparison for the VDR gene is made with different SNPs that are in LD ( $D^{\prime}=1.0$ and $r^{2}=0.59$, based on the HapMap CEU genotyping dataset). In the SLSJ study, the risks are evaluated relative to the VDR-GG and ILIO-TT genotypes. In CAMP, the risks are evaluated relative to the VDRCC and ILIO-TT genotypes.

typing dataset). The gene-gene interaction models were similar between the two studies. The effect of the IL10 variant on asthma seemed dependent on the VDR variant. This can be appreciated in Figure 6 by comparing the solid, dotted and dashed lines between studies. The flipflop phenomenon previously observed in the VDR gene between the SLSJ and CAMP studies [21,22] can also be appreciated in Figure 6 (the solid line is at the top in the SLSJ study and at the bottom in the CAMP study).

\section{Combined analyses}

Single SNP association tests and two-gene models were tested in the combined dataset. Overall, none of the SNPs are significantly associated with asthma or atopy after corrections for multiple testing (see Additional file 9). Similarly, the two-gene models for asthma and atopy were not significant (see Additional files 10 and 11, respectively).

\section{Discussion}

We performed a genetic association study between asthma and genes involved in the vitamin D pathway. SNPs located in five genes, including IL10, CYP24A1, IL1RL1, CYP2R1 and CD86, showed modest association with asthma or atopy in an asthma family study derived from the Saguenay-Lac-Saint-Jean population. Exploring genegene interactions in this pathway revealed significant twogene models that refined risk evaluation for asthma. In an attempt to replicate these findings, we evaluated the significant genes in two additional Canadian studies and one
Australian study. Again modest associations were observed for the IL10, CYP24A1 and CD86 genes for asthma or atopy. In general, SNPs showing association were different between studies or the orientation of the risk allele was reversed. Similarly, the significant two-gene models found in the original study were not replicated in the two additional Canadian studies and the Australian study. However, a significant two-gene model involving the IL10 and VDR gene was replicated in the American study.

Overall, no genes or gene-gene interactions in the vitamin D pathway were consistently associated with asthma or atopy across all populations. This can be explained by multiple factors as discussed previously [3,42]. Briefly, asthma was defined differently between populations, including patient self-reported, physician's diagnosis, or a combination of clinical characteristics and objective threshold from methacholine challenges. In addition, the individual studies are either early or late-onset asthma. More specific for the current study, many environmental factors such as sun exposure and dietary vitamin D intake may differ between studies and explained some of the controversies and flip-flop observations. Considering the differences among populations, our replication effort may be more properly labeled as a descriptive study.

A number of SNPs in the IL10 gene surrounding the promoter region and extending up to intron 1 were signifi- 
cantly associated with asthma in the SLSJ collection. All these SNPs were in tight LD and most of the genetic diversity at this locus was captured by only two haplotypes. Based on functional studies [45-50], the three-SNP promoter haplotypes formed by rs 180096 , rs 1800871 , and rs1800872 have been referred as the high and low IL10producing haplotypes. IL10 is known as an anti-inflammatory cytokine [51]. Accordingly, it makes biological sense that a low IL10-producing haplotype would be associated with asthma, which is consistent with most of the literature [39,52-54]. Surprisingly, none of the promoter polymorphisms in IL10 were associated with asthma or atopy in the SAGE and CAPPS populations with the exception of rs1800896, which was associated with asthma in CAPPS. However, the orientation of the risk allele was reversed compared to what was observed in the SLSJ study and the vast majority of the scientific literature. In contrast, SNPs located in the $3^{\prime}$ end of the IL10 gene (rs3024498 and rs3024492) were associated with asthma in the replicate samples. The functional consequences of these SNPs are unknown but they were previously associated with serum levels of calcidiol $\left(25-\mathrm{OH}-\mathrm{D}_{3}\right)$, the prehormone form of vitamin D [55], and with longitudinal decline rate of lung function [56].

Other genes in the vitamin D pathway tested in the current study have been previously associated with asthma or asthma-related phenotypes. In the German Asthma Family Study, Wjst et al. [55] identified SNPs in the IL10 gene but also in the GC, CYP2R1 and CYP24A1 genes that were significantly associated with asthma or IgE levels. Interestingly, SNPs in these genes were also associated with serum levels of calcidiol $\left(25-\mathrm{OH}-\mathrm{D}_{3}\right)$ and calcitriol $\left[1 \alpha, 25(\mathrm{OH})_{2} \mathrm{D}_{3}\right]$. In the SLSJ population, three SNPs in the CYP24A1 gene showed modest evidence of association with asthma or atopy $(\mathrm{p}<0.05)$. In addition, the only CYP24A1 SNP (rs2248359) genotyped in common between the German and SLSJ population showed a consistent result with an increase risk of asthma associated with the C allele. SNPs in the CYP2R1 gene, encoding an enzyme implicated in earlier steps of the vitamin D metabolic pathway, were also associated with asthma in both the German and the SLSJ studies. Only one SNP in the CD86 and CD28 genes reached significance in the SLSJ population. The CD28 and CD86 interaction represents an important costimulatory signaling pathway for CD4 positive $\mathrm{T}$ cell activation and Th2 cytokine production [57]. The association between atopy and the CD86 promoter polymorphism rs2715267 was relatively strong in the SLSJ collection $(\mathrm{p}=0.004)$. Different SNPs in the CD86 gene were also associated with asthma in the CAPPS and BHS studies. Thus, evidence is building to implicate CD86 as a susceptibility gene for asthma, but independent replications in larger population samples are required. In contrast, the overall results for $C D 28$ are more consistent with the previous studies showing the lack of association with asthma [58-60]. Many SNPs in the IL1RL1 gene were associated with asthma in the SLSJ study. This receptor is required for the development of an effective Th2 response $[61,62]$ and mediates the biological effects of IL-33 [63]. A functional promoter polymorphism (rs6543116) in the IL1RL1 gene was previously associated with atopic dermatitis and high total IgE levels in the sera from the same patients [64]. More recently, a genome-wide association scan for blood eosinophil count identified a strong association with an intronic SNP (rs1420101) in this gene [65]. The same SNP was then associated with asthma in a collection of ten different populations $(7,996$ cases and 44,890 controls). This SNP was not genotyped in the current study, but rs950880 can be used as a surrogate $\left(\mathrm{r}^{2}=\right.$ 0.96 based on the European HapMap data). rs950880 was not associated with asthma or atopy in any of the four populations evaluated in the current study. However, a trend ( $\mathrm{p} \leq 0.10)$ in the same direction as the eosinophil/ asthma study [65] was observed for asthma and atopy in the SLSJ study as well as for atopy in the BHS. Finally, the SLSJ results do not support previous observations with the GC and IL8 genes [55,66,67].

It is reasonable to expect interactions among functionally related genes. In the SLSJ study, some two-gene models were more efficient at evaluating the risk of asthma compared with single SNP models. The models implicating functional variants in the VDR and IL10 genes are particularly interesting. We previously demonstrated that genetic variants in the VDR gene are associated with asthma [21]. Since the latter publication [21], we have genotyped more SNPs in the VDR gene in the same population and many SNPs between intron 2 and exon 9 are associated with asthma (see Additional file 12). The mechanism explaining this association is still unclear, but allele-specific expression at this locus implicates the presence of genetic variants that influence VDR expression [68]. In fact, we observed that the highly expressed haplotype was overtransmitted to asthmatic individuals, while the low expressed haplotype was undertransmitted [3]. These VDR haplotypes can be tagged by the SNP rs 1544410 with the $G$ allele being associated with the high-risk/high-expressed haplotype and the A allele being associated with the low-risk/low-expressed haplotype. As mentioned above, the low IL10-producing haplotype was associated with asthma in the same population (SLSJ). These IL10 haplotypes can be tagged by the SNP rs 1800871 with the $\mathrm{T}$ allele being associated with the high-risk/low-producing haplotype and the $\mathrm{C}$ allele being associated with the low-risk/high-production haplotype. By combining the information of both SNPs (IL10rs1800871 and VDR-rs1544410) we obtained the twogene model shown in Figure $5 \mathrm{~b}$ and that was a significant $(p=0.00018)$ predictor of the risk of asthma. In this 
model, the risk of asthma increased additively with the number of $\mathrm{G}$ alleles (tagging the high-risk/high-expressed haplotype) at the VDR locus and with the number of $\mathrm{T}$ alleles (tagging the high-risk/low-producing haplotype) at the IL10 locus. Similarly, other intriguing interactions between plausible candidate genes were observed in the SLSJ population, including IL10 and IL1RL1 (Figure 5d) as well as IL10 and CD86 (Figure 5e). Although interesting, the large majority of these two-gene models were not replicated in the other populations. In the CAMP study, a two gene-model involving $I L 10$ and VDR variants mirrored the observation made in the SLSJ sample. However, further work will be required to demonstrate the relevance of these two-gene models in asthma.

The cascade of enzymatic reactions that lead to the biosynthesis of $1 \alpha, 25(\mathrm{OH})_{2} \mathrm{D}_{3}$ is complex and requires the participation of many gene products (Figure 1). It is conceivable that polymorphisms in any of several genes in this pathway could lead to differences in endogenous biosynthesis and bioavailability of $1 \alpha, 25(\mathrm{OH})_{2} \mathrm{D}_{3}$. At a more downstream step in the pathway, genetic variants in the $V D R$ itself or in genes implicated in the transcriptional machinery, can influence the sensitivity of the $1 \alpha, 25(\mathrm{OH})_{2} \mathrm{D}_{3}$ stimulus. Further downstream are transcriptionally regulated genes, or vitamin responsive genes, that mediate the broad physiological actions of $1 \alpha, 25(\mathrm{OH})_{2} \mathrm{D}_{3}$. Again, polymorphisms in these genes are prime candidates to influence the vitamin $\mathrm{D}$ response. However, at this level the task is rather challenging owing to the large number of genes regulated by $1 \alpha, 25(\mathrm{OH})_{2} \mathrm{D}_{3}$ [14]. An extra layer of complexity exists, knowing that the regulation of gene expression by $1 \alpha, 25(\mathrm{OH})_{2} \mathrm{D}_{3}$ is highly cell-specific $[69,70]$. Accordingly, a large number of genes can determine the overall response to the vitamin D pathway. With this in perspective, gene selection in the current study was not comprehensive. On the other hand, the results of the current study may have implications in a wider scope than the field of asthma and asthma-related phenotypes. SNPs associated with asthma in the vitamin $\mathrm{D}$ pathway genes may influence the overall vitamin $\mathrm{D}$ sensitivity and consequently influence many other diseases [55].

\section{Conclusion}

Cumulative observations implicate the vitamin D pathway in immune responses. By studying genes involved in this pathway, we identified genetic polymorphisms modestly associated with asthma and atopy in asthmatic families from the Saguenay-Lac-Saint-Jean region. Significant two-gene models that include interactions between components of the pathway were also identified. We then attempted to replicate the findings in two additional Canadian studies and one Australian study. Similar to the SLSJ study, some SNPs in the IL10 and CYP24A1 genes were modestly associated with asthma or atopy. However, the SNPs or the orientation of the risk alleles were different between populations. It is conceivable that the effect of the VDR system in immune responses can be overruled by more potent immune pathways. Accordingly, the effect of the vitamin D pathway might be detectable only in specific environments or age-related contexts. Further studies are warranted to confirm the single SNP and the multilocus models associated with asthma in the current study.

\section{List of abbreviations used}

BHS: Busselton Health Study; CAMP: Childhood Asthma Management Program; CAPPS: Canadian Asthma Primary Prevention Study; CD28: CD28 molecule; CD86: CD86 molecule; CYP24A1: cytochrome P450, family 24, subfamily A, polypeptide 1; CYP27A1: cytochrome P450, family 27, subfamily A, polypeptide 1; CYP27B1: cytochrome P450, family 27, subfamily $\mathrm{B}$, polypeptide 1; CYP2R1: cytochrome P450, family 2, subfamily $R$, polypeptide 1; FBAT: family based association test; $\mathrm{FEV}_{1}$ : forced expiratory volume in 1 second; GC: vitamin D binding protein; IL10: interleukin 10; IL1RL1: interleukin 1 receptor-like 1 ; IL8: interleukin 8 ; LD: linkage disequilibrium; NHS: Nurses' Health Study; PC20: the concentration of methacholine that causes a $20 \%$ decline in $\mathrm{FEV}_{1}$; SAGE: Study of Asthma Genes and the Environment; SKIIP: SKI interacting protein; SLSJ: Saguenay-Lac-SaintJean; SNP: single-nucleotide-polymorphism; VDR: vitamin $\mathrm{D}$ receptor.

\section{Competing interests}

The authors declare that they have no competing interests.

\section{Authors' contributions}

YB carried out gene/SNP selection, genotyping in the SLSJ study, integration of datasets and was primary author of the manuscript. ML performed statistical analyses in SLSJ, SAGE, CAPPS, and BHS. AHP carried out statistical analyses in CAMP. DD, JQH and AS provided statistical, genotyping and genetics expertise to replicate the findings in the AllerGen study samples. JHW made substantial intellectual contribution in gene selection. ALJ, AWM and LJP participated in the conception and coordination of the BHS. BAR and STW participated in the conception and coordination of CAMP. ALK participated in the coordination of the SAGE study. AB conceived and acquired funding for the SAGE and CAPPS studies. TJH and CL conceived and acquired funding for the SLSJ study. TJH also provided general supervision of the research group. All authors read and approved the final manuscript. 


\section{Additional material}

\section{Additional file 1}

SNP characteristics. Table showing the SNPs selected for genotyping and their characteristics including chromosomal location, type of variation, minor allele, minor allele frequency, and Hardy-Weinberg $p$ value. Click here for file

[http://www.biomedcentral.com/content/supplementary/14659921-10-98-S1.DOC]

\section{Additional file 2}

Genetic association of SNPs in the vitamin D pathway genes with asthma and atopy in the SLSJ study. Each subfigure presents the result of one gene. The top line indicates the gene name and symbol. The upper part of each subfigure shows the exon-intron structure of the gene and the localization of the genotyped SNPs. The coding exons are shown in black and the untranslated regions are shown in grey. The lower part of each subfigure illustrates the association results for asthma (solid circles) and atopy (open circles). The $x$-axis shows the localization of the gene and SNPs on NCBI Human Genome build 35. The y-axis shows the FBAT empirical $p$ values on a $\log _{10}$ scale. The lower and upper dashed lines represent $p$ value thresholds of 0.05 and 0.001 , respectively. The upper and lower parts of each subfigure are shown on the same scale.

Click here for file

[http://www.biomedcentral.com/content/supplementary/14659921-10-98-S2.JPEG]

\section{Additional file 3}

The overall distribution of $p$ values derived from single marker FBAT association tests in the SLSJ study. The top panels are Q-Q plots showing the distribution of observed $p$ values against the expected distribution for asthma and atopy. The bottom panels are histograms showing the distribution of $p$ values for asthma and atopy. The dashed lines represent the mean number of $p$ values that is expected by chance. Association test results for 83 SNPs located in 11 genes are illustrated.

Click here for file

[http://www.biomedcentral.com/content/supplementary/14659921-10-98-S3.JPEG]

\section{Additional file 4}

Single SNP association results for asthma and atopy in the Saguenay-Lac-Saint-Jean study. Table showing the FBAT results for all SNPs in the Saguenay-Lac-Saint-Jean study.

Click here for file

[http://www.biomedcentral.com/content/supplementary/14659921-10-98-S4.DOC]

\section{Additional file 5}

Linkage disequilibrium (LD) plots surrounding eleven genes involved in the vitamin D pathway in the SLSJ study. The LD plots were generated by Haploview 3.32 [41]. Gene symbols are indicated at the top of each graph. The top horizontal bar illustrates the location of SNPs on a physical scale. The color of squares illustrates the strength of pairwise $r^{2}$ values on a black and white scale where black indicates perfect $L D\left(r^{2}=\right.$ $1.00)$ and white indicates perfect equilibrium $\left(r^{2}=0\right)$. The $r^{2} L D$ value is also indicated within each square. Blocks are defined using the Gabriel et al [71] definition. Failed and monomorphic SNPs as well as SNPs not in Hardy-Weinberg equilibrium are not illustrated.

Click here for file

[http://www.biomedcentral.com/content/supplementary/14659921-10-98-S5.DOC]

\section{Additional file 6}

Two-gene model analyses on atopy in the SLSJ study. Visual representation of results is explained in Figure 4.

Click here for file

[http://www.biomedcentral.com/content/supplementary/14659921-10-98-S6.JPEG]

\section{Additional file 7}

Single SNP association results for asthma and atopy in the replication samples. Table showing the results for all SNPs in the replication samples. Click here for file

[http://www.biomedcentral.com/content/supplementary/14659921-10-98-S7.DOC]

\section{Additional file 8}

Two-gene model analyses on asthma in the BHS. Visual representation of results is explained in Figure 4.

Click here for file

[http://www.biomedcentral.com/content/supplementary/14659921-10-98-S8.JPEG]

\section{Additional file 9}

Single SNP association results for asthma and atopy in combined analyses (SLSJ, CAPPS, SAGE, and BHS). Table showing the results for the combined analyses.

Click here for file

[http://www.biomedcentral.com/content/supplementary/14659921-10-98-S9.DOC]

\section{Additional file 10}

Two-gene model analyses on asthma in the combined dataset for genes involved in the vitamin D pathway. Visual representation of results is explained in Figure 4.

Click here for file

[http://www.biomedcentral.com/content/supplementary/14659921-10-98-S10.JPEG]

\section{Additional file 11}

Two-gene model analyses on atopy in the combined dataset for genes involved in the vitamin $D$ pathway. Visual representation of results is explained in Figure 4.

Click here for file

[http://www.biomedcentral.com/content/supplementary/14659921-10-98-S11.JPEG]

\section{Additional file 12}

Genetic association between SNPs in the vitamin D receptor gene and asthma in the SLSJ study. The upper part of the figure shows the exonintron structure of the gene and the localization of the genotyped SNPs. The coding exons are shown in black and the untranslated regions are shown in grey. The lower part of the figure illustrates the association results for asthma. The $x$-axis shows the localization of the gene and SNPs on NCBI Human Genome build 35. The $y$-axis shows the FBAT empirical $p$ values on a $\log _{10}$ scale. The lower and upper dashed lines represent $p$ value thresholds of 0.05 and 0.001 , respectively. The upper and lower parts of the figure are shown on the same scale.

Click here for file

[http://www.biomedcentral.com/content/supplementary/14659921-10-98-S12.JPEG] 


\section{Acknowledgements}

We gratefully acknowledge Peter D Paré for in-depth review of the manuscript. Y. Bossé was the recipient of a fellowship award from the Canadian Institutes of Health and Research (CIHR) and is currently a research scholar from the Heart and Stroke Foundation of Canada. A.H. Poon is recipient of a fellowship award from the Croucher Foundation. D. Daley was the recipient of a fellowship award from the CIHR and is currently holding a Canada Research Chair on the Genetic Epidemiology of Complex Diseases and a Michael Smith Career Scholar Award. A. Sandford is the recipient of a Canada Research Chair in genetics. J.H. White is supported by a National Scientist Award from the "Fonds de la Recherche en Santé du Québec" (FRSQ). B.A. Raby is a recipient of a Mentored Clinical Scientist Development Award from NIH/NHLBI (K08 HL074 193). T.J. Hudson is currently funded by a Senior Investigator Award of the Ontario Institute for Cancer Research and was the recipient of a Clinician-Scientist Award in Translational Research by the Burroughs Wellcome Fund and an Investigator Award from the Canadian Institutes of Health Research. C. Laprise is the chairholder of the Canada Research Chair on genetic determinants in asthma and the director of the Inflammation and Remodeling Strategic Group of the Respiratory Health Network of the FRSQ, which partially support the French Canadian study. Additional support for this study came from the Networks of Centres of Excellence, Allergy, Genes and Environment Network (AllerGen). We acknowledge the CAMP investigators and research team, supported by NHLBI, for collection of CAMP Genetic Ancillary Study data. All work on data collected from the CAMP Genetic Ancillary Study was conducted at the Channing Laboratory of the Brigham and Women's Hospital under appropriate CAMP policies and human subject's protections. The CAMP Genetics Ancillary Study is supported by UOI HL0754 I9, U0I HL65899, POI HL083069, ROI HL 08660I, and T32 HL07427 from the National Heart, Lung and Blood Institute, National Institutes of Health. Additional support for this research came from AllerGen. A. Becker, Y. Bossé, D. Daley, J.-Q. He, T.J. Hudson, A.L. James, A.L. Kozyrskyj, C. Laprise, M. Lemire, A.W. Musk, L.J. Palmer, P.D. Paré and A. Sandford are members of AllerGen. The Busselton Health Study received support from Healthway, Western Australia for the 1994 re-survey. The Busselton Health Study acknowledges the study participants and local voluntary survey staff.

\section{References}

I. National Asthma Education and Prevention Program. Expert Panel Report: Guidelines for the Diagnosis and Management of Asthma Update on Selected Topics--2002. J Allergy Clin Immunol 2002, I I O(5 SuppI):SI4I-2I9.

2. Manian P: Genetics of asthma: a review. Chest 1997, I I 2(5): I 397-| 408.

3. Bosse $Y$, Hudson T]: Toward a comprehensive set of asthma susceptibility genes. Annu Rev Med 2007, 58: I7I- I84.

4. Ober C, Hoffjan S: Asthma genetics the long and winding road to gene discovery. Genes Immun 2006, 7(2):95-100.

5. Zhang J, Pare PD, Sandford AJ: Recent advances in asthma genetics. Respir Res 2008, 9:4.

6. Moffatt MF, Kabesch M, Liang L, Dixon AL, Strachan D, Heath S, Depner $M$, von Berg $A$, Bufe A, Rietschel E, Heinzmann A, Simma B, Frischer T, Willis-Owen SA, Wong KC, Illig T, Vogelberg C, Weiland SK, von Mutius E, Abecasis GR, Farrall M, Gut IG, Lathrop GM, Cookson WO: Genetic variants regulating ORMDL3 expression contribute to the risk of childhood asthma. Nature 2007, 448(7 I 52):470-473.

7. Ober C, Tan Z, Sun Y, Possick JD, Pan L, Nicolae R, Radford S, Parry RR, Heinzmann A, Deichmann KA, Lester LA, Gern JE, Lemanske RF Jr, Nicolae DL, Elias JA, Chupp GL: Effect of variation in CHI3L I on serum YKL-40 level, risk of asthma, and lung function. The New England journal of medicine 2008, 358(16): I682-I69I.

8. Weidinger S, Gieger C, Rodriguez E, Baurecht H, Mempel M, Klopp N, Gohlke H, Wagenpfeil S, Ollert M, Ring J, Behrendt H, Heinrich J, Novak N, Bieber T, Kramer U, Berdel D, von Berg A, Bauer CP, Herbarth O, Koletzko S, Prokisch H, Mehta D, Meitinger T, Depner M, von Mutius E, Liang L, Moffatt M, Cookson W, Kabesch M, Wichmann $\mathrm{HE}$, et al.: Genome-wide scan on total serum IgE levels identifies FCERIA as novel susceptibility locus. PLOS Genet 2008, 4(8): el 000166.

9. Liu PT, Stenger S, Li H, Wenzel L, Tan BH, Krutzik SR, Ochoa MT, Schauber J, Wu K, Meinken C, Kamen DL, Wagner M, Bals R, Steinmeyer A, Zugel U, Gallo RL, Eisenberg D, Hewison M, Hollis BW, Adams JS, Bloom BR, Modlin RL: Toll-like receptor triggering of a vitamin D-mediated human antimicrobial response. Science 2006, 3 I I(5768): I 770- I 773.

10. Cantorna MT, Zhu Y, Froicu M, Wittke A: Vitamin D status, I, 25dihydroxyvitamin D3, and the immune system. Am J Clin Nutr 2004, 80(6 Suppl): I7I 7S-I720S

II. Hayes CE, Nashold FE, Spach KM, Pedersen LB: The immunological functions of the vitamin $D$ endocrine system. Cell Mol Biol (Noisy-le-grand) 2003, 49(2):277-300.

12. White JH: Vitamin D signaling, infectious diseases, and regulation of innate immunity. Infect Immun 2008, 76(9):3837-3843.

13. Dusso AS, Brown AJ, Slatopolsky E: Vitamin D. Am J Physiol Renal Physiol 2005, 289(I):F8-28.

14. Wang TT, Tavera-Mendoza LE, Laperriere D, Libby E, MacLeod NB, Nagai Y, Bourdeau V, Konstorum A, Lallemant B, Zhang R, Mader S, White JH: Large-scale in silico and microarray-based identification of direct I,25-dihydroxyvitamin D3 target genes. Mol Endocrinol 2005, I 9(I I):2685-2695.

15. Hewison M, Freeman L, Hughes SV, Evans KN, Bland R, Eliopoulos AG, Kilby MD, Moss PA, Chakraverty R: Differential regulation of vitamin $D$ receptor and its ligand in human monocytederived dendritic cells. J Immunol 2003, I 70( I I ):5382-5390.

16. Veldman CM, Cantorna MT, DeLuca HF: Expression of I,25-dihydroxyvitamin $D(3)$ receptor in the immune system. Arch Biochem Biophys 2000, 374(2):334-338.

17. D'Ambrosio D, Cippitelli M, Cocciolo MG, Mazzeo D, Di Lucia P, Lang R, Sinigaglia F, Panina-Bordignon P: Inhibition of IL- 12 production by I,25-dihydroxyvitamin D3. Involvement of NFkappaB downregulation in transcriptional repression of the p40 gene. J Clin Invest 1998, I 0 I(I):252-262.

18. Overbergh L, Decallonne B, Waer M, Rutgeerts O, Valckx D, Casteels KM, Laureys J, Bouillon R, Mathieu C: I alpha,25-dihydroxyvitamin D3 induces an autoantigen-specific T-helper I/T. helper 2 immune shift in NOD mice immunized with GAD65 (p524-543). Diabetes 2000, 49(8): | 301-1307.

19. Wittke A, Weaver V, Mahon BD, August A, Cantorna MT: Vitamin $D$ receptor-deficient mice fail to develop experimental allergic asthma. J Immunol 2004, I 73(5):3432-3436.

20. van Etten E, Verlinden L, Giulietti A, Ramos-Lopez E, Branisteanu DD, Ferreira GB, Overbergh L, Verstuyf A, Bouillon R, Roep BO, Badenhoop K, Mathieu C: The vitamin D receptor gene Fokl polymorphism: functional impact on the immune system. Eur J Immunol 2007, 37(2):395-405.

21. Poon AH, Laprise C, Lemire M, Montpetit A, Sinnett D, Schurr E, Hudson TJ: Association of vitamin $D$ receptor genetic variants with susceptibility to asthma and atopy. Am J Respir Crit Care Med 2004, I 70(9):967-973.

22. Raby BA, Lazarus R, Silverman EK, Lake S, Lange C, Wjst M, Weiss ST: Association of vitamin D receptor gene polymorphisms with childhood and adult asthma. Am J Respir Crit Care Med 2004, I 70(10): 1057-1065.

23. Millstein J, Conti DV, Gilliland FD, Gauderman WJ: A testing framework for identifying susceptibility genes in the presence of epistasis. Am J Hum Genet 2006, 78(I): I 5-27.

24. Schaid DJ, McDonnell SK, Hebbring SJ, Cunningham JM, Thibodeau $\mathrm{SN}$ : Nonparametric tests of association of multiple genes with human disease. Am J Hum Genet 2005, 76(5):780-793.

25. Skin tests used in type I allergy testing Position paper. SubCommittee on Skin Tests of the European Academy of Allergology and Clinical Immunology. Allergy I989, 44(Suppl I0): I-59.

26. Begin P, Tremblay K, Daley D, Lemire M, Claveau S, Salesse C, Kacel S, Montpetit A, Becker A, Chan-Yeung M, Kozyrskyj AL, Hudson T], Laprise C: Association of urokinase-type plasminogen activator with asthma and atopy. Am J Respir Crit Care Med 2007, I75(I I): I I09-III6.

27. Chan-Yeung M, Manfreda J, Dimich-Ward H, Ferguson A, Watson W, Becker A: A randomized controlled study on the effectiveness of a multifaceted intervention program in the primary pre- 
vention of asthma in high-risk infants. Arch Pediatr Adolesc Med 2000, I 54(7):657-663.

28. Chan-Yeung M, Ferguson A, Watson W, Dimich-Ward H, Rousseau R, Lilley M, Dybuncio A, Becker A: The Canadian Childhood Asthma Primary Prevention Study: outcomes at 7 years of age. J Allergy Clin Immunol 2005, I I 6(I):49-55.

29. The Childhood Asthma Management Program (CAMP) design, rationale, and methods. Childhood Asthma Management Program Research Group. Control Clin Trials 1999, 20(I):9I-I 20 .

30. Long-term effects of budesonide or nedocromil in children with asthma. The Childhood Asthma Management Program Research Group. The New England journal of medicine 2000, 343(15): 1054-1063.

3I. Lin R, White JH: The pleiotropic actions of vitamin D. Bioessays 2004, 26(I):2I-28.

32. Prosser DE, Jones G: Enzymes involved in the activation and inactivation of vitamin D. Trends Biochem Sci 2004, 29(12):664-673.

33. MacDonald PN, Dowd DR, Zhang C, Gu C: Emerging insights into the coactivator role of NCoA62/SKIP in Vitamin D-mediated transcription. I Steroid Biochem Mol Biol 2004, 89-90(I5): $179-186$.

34. A haplotype map of the human genome. Nature 2005, 437(7063): $1299-1320$.

35. Carlson CS, Eberle MA, Rieder MJ, Yi Q, Kruglyak L, Nickerson DA: Selecting a maximally informative set of single-nucleotide polymorphisms for association analyses using linkage disequilibrium. Am J Hum Genet 2004, 74(I): I06-120.

36. Bell PA, Chaturvedi S, Gelfand CA, Huang CY, Kochersperger M, Kopla R, Modica F, Pohl M, Varde S, Zhao R, Zhao X, Boyce-Jacino MT, Yassen A: SNPstream UHT: ultra-high throughput SNP genotyping for pharmacogenomics and drug discovery. Biotechniques 2002:70-77. 74, 76-77

37. Kalendar R: FastPCR: a PCR primer design and repeat sequence searching software with additional tools for the manipulation and analysis of DNA and protein. 2004 [http:// www.biocenter.helsinki.fi/bi/programs/fastpcr.htm].

38. Oliphant A, Barker DL, Stuelpnagel JR, Chee MS: BeadArray technology: enabling an accurate, cost-effective approach to high-throughput genotyping. Biotechniques 2002:56-6I. 60-6I

39. Lyon H, Lange C, Lake S, Silverman EK, Randolph AG, Kwiatkowski D, Raby BA, Lazarus R, Weiland KM, Laird N, Weiss ST: ILI 0 gene polymorphisms are associated with asthma phenotypes in children. Genet Epidemiol 2004, 26(2): I55-165.

40. Horvath S, Xu X, Lake SL, Silverman EK, Weiss ST, Laird NM: Family-based tests for associating haplotypes with general phenotype data: application to asthma genetics. Genet Epidemiol 2004, 26(I):6I-69.

41. Barrett JC, Fry B, Maller J, Daly MJ: Haploview: analysis and visualization of LD and haplotype maps. Bioinformatics 2005, 2I(2):263-265.

42. Daley D, Lemire M, Akhabir L, Chan-Yeung M, He JQ, McDonald T, Sandford A, Stefanowicz D, Tripp B, Zamar D, Bosse Y, Ferretti V, Montpetit A, Tessier MC, Becker A, Kozyrskyj AL, Beilby J, McCaskie PA, Musk B, Warrington N, James A, Laprise C, Palmer LJ, Pare PD, Hudson TJ: Analyses of associations with asthma in four asthma population samples from Canada and Australia. Hum Genet 2009, I 25(4):445-459.

43. Cordell HJ, Barratt BJ, Clayton DG: Case/pseudocontrol analysis in genetic association studies: A unified framework for detection of genotype and haplotype associations, gene-gene and gene-environment interactions, and parent-of-origin effects. Genet Epidemiol 2004, 26(3):167-185.

44. Dudbridge F: Likelihood-based association analysis for nuclear families and unrelated subjects with missing genotype data. Hum Hered 2008, 66(2):87-98.

45. Shin HD, Winkler C, Stephens JC, Bream J, Young H, Goedert JJ, O'Brien TR, Vlahov D, Buchbinder S, Giorgi ], Rinaldo C, Donfield S, Willoughby A, O'Brien SJ, Smith MW: Genetic restriction of HIVI pathogenesis to AIDS by promoter alleles of ILIO. Proc Natl Acad Sci USA 2000, 97(26): | 4467-14472.

46. Crawley E, Kay R, Sillibourne J, Patel P, Hutchinson I, Woo P: Polymorphic haplotypes of the interleukin- 105 ' flanking region determine variable interleukin-10 transcription and are associated with particular phenotypes of juvenile rheumatoid arthritis. Arthritis Rheum 1999, 42(6): I I0I-I I08.

47. Rosenwasser LJ, Borish L: Genetics of atopy and asthma: the rationale behind promoter-based candidate gene studies (IL4 and IL-10). Am J Respir Crit Care Med 1997, I 56(4 Pt 2):SI 52-I55.

48. Hajeer AH, Lazarus M, Turner D, Mageed RA, Vencovsky J, Sinnott P, Hutchinson IV, Ollier WE: IL- 10 gene promoter polymorphisms in rheumatoid arthritis. Scand J Rheumatol 1998, 27(2): I $42-145$.

49. Turner DM, Williams DM, Sankaran D, Lazarus M, Sinnott PJ, Hutchinson IV: An investigation of polymorphism in the interleukin10 gene promoter. Eur J Immunogenet 1997, 24(I): I-8.

50. Zhang J, Chen $\mathrm{H}$, Hu L, Fu ], Zhang $\mathrm{H}$, Chen $\mathrm{Y}$ : [Correlation between polymorphism of IL-4 and IL- I 0 gene promoter and childhood asthma and their impact upon cytokine expression]. Zhonghua Yi Xue Za Zhi 2002, 82(2):। | 4-| I8.

5I. Moore KW, de Waal Malefyt R, Coffman RL, O'Garra A: Interleukin- 10 and the interleukin- 10 receptor. Annu Rev Immunol 200I, 19:683-765.

52. Hobbs K, Negri J, Klinnert M, Rosenwasser LJ, Borish L: Interleukin10 and transforming growth factor-beta promoter polymorphisms in allergies and asthma. Am J Respir Crit Care Med 1998, 158(6): 1958-1962.

53. Lim S, Crawley E, Woo P, Barnes PJ: Haplotype associated with low interleukin-10 production in patients with severe asthma. Lancet 1998, 352(9 | 22): I I3.

54. Karjalainen J, Hulkkonen J, Nieminen MM, Huhtala H, Aromaa A Klaukka T, Hurme M: Interleukin- 10 gene promoter region polymorphism is associated with eosinophil count and circulating immunoglobulin E in adult asthma. Clin Exp Allergy 2003, 33(I):78-83.

55. Wist M, Altmuller J, Faus-Kessler T, Braig C, Bahnweg M, Andre E: Asthma families show transmission disequilibrium of gene variants in the vitamin $D$ metabolism and signalling pathway. Respir Res 2006, 7:60.

56. Burgess JL, Fierro MA, Lantz RC, Hysong TA, Fleming JE, Gerkin R, Hnizdo E, Conley SM, Klimecki W: Longitudinal decline in lung function: evaluation of interleukin-lO genetic polymorphisms in firefighters. J Occup Environ Med 2004, 46(10): $1013-1022$.

57. Van Neerven RJ, Pol MM Van de, Zee JS Van der, Stiekema FE, De Boer M, Kapsenberg ML: Requirement of CD28-CD86 costimulation for allergen-specific $T$ cell proliferation and cytokine expression. Clin Exp Allergy 1998, 28(7):808-816.

58. Heinzmann A, Plesnar C, Kuehr J, Forster J, Deichmann KA: Common polymorphisms in the CTLA-4 and CD28 genes at $2 q 33$ are not associated with asthma or atopy. Eur J Immunogenet 2000, 27(2):57-61.

59. Howard TD, Postma DS, Hawkins GA, Koppelman GH, Zheng SL Wysong AK, Xu J, Meyers DA, Bleecker ER: Fine mapping of an IgE-controlling gene on chromosome 2q: Analysis of CTLA4 and CD28. I Allergy Clin Immunol 2002, I I 0(5):743-75I.

60. Nakao F, Ihara K, Ahmed S, Sasaki Y, Kusuhara K, Takabayashi A, Nishima S, Hara T: Lack of association between CD28/CTLA-4 gene polymorphisms and atopic asthma in the Japanese population. Exp Clin Immunogenet 2000, I7(4): 179-184.

61. Lohning M, Stroehmann A, Coyle A), Grogan JL, Lin S, GutierrezRamos JC, Levinson D, Radbruch A, Kamradt T: TI/ST2 is preferentially expressed on murine Th2 cells, independent of interleukin 4, interleukin 5 , and interleukin 10 , and important for Th2 effector function. Proc Natl Acad Sci USA 1998, 95(I 2):6930-6935.

62. Trajkovic V, Sweet MJ, Xu D: TI/ST2--an IL-I receptor-like modulator of immune responses. Cytokine Growth Factor Rev 2004, 15(2-3):87-95.

63. Schmitz J, Owyang A, Oldham E, Song Y, Murphy E, McClanahan TK, Zurawski G, Moshrefi M, Qin J, Li X, Gorman DM, Bazan JF, Kastelein RA: IL-33, an interleukin-I-like cytokine that signals via the IL-I receptor-related protein ST2 and induces Thelper type 2-associated cytokines. Immunity 2005, 23(5):479-490.

64. Shimizu M, Matsuda A, Yanagisawa K, Hirota T, Akahoshi M, Inomata N, Ebe K, Tanaka K, Sugiura H, Nakashima K, Tamari M, Takahashi N, Obara K, Enomoto T, Okayama Y, Gao PS, Huang SK, Tominaga S, Ikezawa Z, Shirakawa T: Functional SNPs in the distal promoter of the ST2 gene are associated with atopic dermatitis. Hum Mol Genet 2005, I 4( I 9):29|9-2927. 
65. Gudbjartsson DF, Bjornsdottir US, Halapi E, Helgadottir A, Sulem P, Jonsdottir GM, Thorleifsson G, Helgadottir H, Steinthorsdottir V, Stefansson H, Williams C, Hui J, Beilby J, Warrington NM, James A, Palmer LJ, Koppelman GH, Heinzmann A, Krueger M, Boezen HM, Wheatley A, Altmuller J, Shin HD, Uh ST, Cheong HS, Jonsdottir B, Gislason D, Park CS, Rasmussen LM, Porsbjerg C, et al.: Sequence variants affecting eosinophil numbers associate with asthma and myocardial infarction. Nat Genet 2009, 4I(3):342-347.

66. Laufs J, Andrason H, Sigvaldason A, Halapi E, Thorsteinsson L, Jonasson K, Soebech E, Gislason T, Gulcher JR, Stefansson K, Hakonarson $\mathrm{H}$ : Association of vitamin D binding protein variants with chronic mucus hypersecretion in Iceland. Am J Pharmacogenomics 2004, 4(I):63-68.

67. Heinzmann A, Ahlert I, Kurz T, Berner R, Deichmann KA: Association study suggests opposite effects of polymorphisms within IL8 on bronchial asthma and respiratory syncytial virus bronchiolitis. J Allergy Clin Immunol 2004, I I 4(3):67I-676.

68. Pastinen T, Ge B, Gurd S, Gaudin T, Dore C, Lemire M, Lepage P, Harmsen E, Hudson TJ: Mapping common regulatory variants to human haplotypes. Hum Mol Genet 2005, I 4(24):3963-397I.

69. Bosse Y, Maghni K, Hudson TJ: I alpha,25-dihydroxy-vitamin D3 stimulation of bronchial smooth muscle cells induces autocrine, contractility, and remodeling processes. Physiol Genomics 2007, 29(2): $161-168$

70. Zhang X, Li P, Bao J, Nicosia SV, Wang H, Enkemann SA, Bai W: Suppression of death receptor-mediated apoptosis by I,25-dihydroxyvitamin D3 revealed by microarray analysis. J Biol Chem 2005, 280(42):35458-35468.

7I. Gabriel SB, Schaffner SF, Nguyen H, Moore JM, Roy J, Blumenstiel B, Higgins J, DeFelice M, Lochner A, Faggart M, Liu-Cordero SN, Rotimi C. Adeyemo A, Cooper R, Ward R, Lander ES, Daly MJ, Altshuler D: The structure of haplotype blocks in the human genome. Science 2002, 296(5576):2225-2229.

Publish with Bio Med Central and every scientist can read your work free of charge

"BioMed Central will be the most significant development for disseminating the results of biomedical research in our lifetime. "

Sir Paul Nurse, Cancer Research UK

Your research papers will be:

- available free of charge to the entire biomedical community

- peer reviewed and published immediately upon acceptance

- cited in PubMed and archived on PubMed Central

- yours - you keep the copyright

Submit your manuscript here:

http://www.biomedcentral.com/info/publishing_adv.asp
BioMedcentral 